\title{
Leader-member Exchange (LMX) ambivalence and task performance: The cross-domain buffering role of social support.
}

DOI:

$10.1177 / 0149206317741190$

\section{Document Version}

Final published version

Link to publication record in Manchester Research Explorer

Citation for published version (APA):

Thomas, G., Martin, R., Lee, A., guillaume, Y., \& epitropaki, O. (2017). Leader-member Exchange (LMX) ambivalence and task performance: The cross-domain buffering role of social support. Journal of Management, 45(5), 1927-1957. https://doi.org/10.1177/0149206317741190

\section{Published in:}

Journal of Management

\section{Citing this paper}

Please note that where the full-text provided on Manchester Research Explorer is the Author Accepted Manuscript or Proof version this may differ from the final Published version. If citing, it is advised that you check and use the publisher's definitive version.

\section{General rights}

Copyright and moral rights for the publications made accessible in the Research Explorer are retained by the authors and/or other copyright owners and it is a condition of accessing publications that users recognise and abide by the legal requirements associated with these rights.

\section{Takedown policy}

If you believe that this document breaches copyright please refer to the University of Manchester's Takedown Procedures [http://man.ac.uk/04Y6Bo] or contact uml.scholarlycommunications@manchester.ac.uk providing relevant details, so we can investigate your claim.

\section{OPEN ACCESS}


Journal of Management

Vol. 45 No. 5, May 2019 1927-1957

DOI: $10.1177 / 0149206317741190$

(C) The Author(s) 2017

Article reuse guidelines:

sagepub.com/journals-permissions

\title{
Leader-Member Exchange (LMX) Ambivalence and Task Performance: The Cross-Domain Buffering Role of Social Support
}

\author{
Allan Lee \\ University of Exeter \\ Geoff Thomas \\ University of Surrey \\ Robin Martin \\ University of Manchester \\ Yves Guillaume \\ University of Liverpool
}

Leader-member exchange (LMX) theory proposes that leaders develop different quality relationships with those they manage and this is predictive of work performance. While LMX quality has been viewed as univalent (ranging from low to high quality), this paper proposes that it can also be bivalent in nature (i.e., coexisting positive and negative thoughts towards the relationship), which we refer to as LMX ambivalence. A survey measure of LMX ambivalence is developed, and through three validation and two main studies, it is shown to have construct, discriminant, and incremental predictive validity beyond that of LMX quality. Hypotheses concerning LMX ambivalence and task performance are tested in two main studies and show that (1) LMX ambivalence is negatively related to performance regardless of LMX quality, (2) high levels of perceived support from the organization (Study 1) or coworkers (Study 2) nullify the negative association between LMX ambivalence and performance, and (3) high LMX ambivalence leads to more negative affect and in turn lower task performance, but only when coworker support is low (Study 2). These results show the importance of viewing LMX quality not only in terms of its absolute level (low vs. high quality) but also as a bivalent construct where both

\footnotetext{
Acknowledgments: This article was accepted under the editorship of Patrick M. Wright. The authors would like to thank the editor, Christopher Porter, and the two anonymous reviewers for their thoughtful, supportive, and developmental comments.

Supplemental material for this article is available with the manuscript on the JOM website.

Corresponding author: Allan John Robin Lee, Business School, University of Exeter, Rennes Drive, Exeter, EX4 4PU, England.

E-mail:allan.lee@exeter.ac.uk
} 
positive and negative cognitions can coexist. They also demonstrate the value of social support in buffering the negative effects of LMX ambivalence. Furthermore, our findings extend a central tenet of LMX theory by implying that LMX quality varies not only within groups (i.e., LMX differentiation) but also within leader-follower dyads.

Keywords: leader-member exchange; LMX; ambivalence; performance; negative affect; workplace relationships; social support; variability

I hate and yet love. You may wonder how I manage it. I don't know, but feel it happen, and am in torment.

The above quote eloquently illustrates the potential for felt ambivalence- the simultaneous experience of both positive and negative orientations towards a person, relationship, idea, or indeed any entity - to elicit aversive consequences. Ambivalence is a concept that has received a good deal of research interest in the social sciences (Baek, 2010) and increasing interest in the field of management (Rothman, Pratt, Rees, \& Vogus, 2017). Given that ambivalence may "be more the norm than the exception in organizations" (Rothman et al., 2017: 33), it is surprising that its effects on employee behavior are still poorly understood (Ashforth, Rogers, Pratt, \& Pradies, 2014). Furthermore, despite initial evidence of the deleterious impact of ambivalent job attitudes (e.g., Ziegler, Hagen, \& Diehl, 2012) and ambivalent organizational identification (e.g., Pratt, 2000), little is known about the factors that may help to ameliorate these potential negative effects.

To fill this lacuna, we propose that a valuable starting point is to examine ambivalence within the context of workplace relationships and, in particular, leader-follower relationships. Relationship scientists have long recognized that highly interdependent relationships (in any domain) are especially prone to eliciting ambivalence, resulting in dysfunctional and negative outcomes (e.g., Fincham \& Linfield, 1997). In line with this reasoning, one of the most central and interdependent relationships at work, at least for followers, is the leader-follower relationship (Thomas, Martin, Epitropaki, Guillaume, \& Lee, 2013). According to leader-member exchange (LMX) theory, followers are highly dependent on the quality of their LMX relationships as these relationships are critical to their achievements and future prospects in the organization (Sparrowe \& Liden, 2005). Moreover, LMX relationships are, to a certain extent, paradoxical by nature because leaders and followers routinely seek interpersonal closeness while simultaneously seeking to preserve hierarchical distinctions (Zhang, Waldman, Han, \& Li, 2015), making the LMX relationship a crucial context in which to explore ambivalence.

Drawing on theories and research related to LMX (Graen \& Uhl-Bien, 1995) and ambivalence (e.g., van Harreveld, Nohlen, \& Schneider, 2015), we argue that LMX ambivalencethe subjective experience of coexisting positive and negative thoughts towards the leader-follower relationship - is likely to have important implications for task performance. The central premise of LMX theory is that leaders develop different quality relationships with each of their followers, with low LMX quality representing mainly economic or transactional exchanges and high LMX quality representing predominantly social exchanges (Dansereau, Graen, \& Haga, 1975). In the case of high LMX quality, the favorable treatment 
the follower receives from the leader engenders feelings of obligation to reciprocate by performing better (Blau, 1964; Sparrowe \& Liden, 1997). However, by conceptualizing the leader-follower relationship on a continuum ranging from low to high quality, LMX theory has implicitly assumed that the relationship is univalent (rather than bivalent) in nature. Consequently, LMX theory, in its original form, is unable to explain the performance implications of ambivalent leader-follower relationships. Instead, the literature on ambivalence suggests that the experience of relational ambivalence can undermine task performance (e.g., Pratt, 2000), particularly if it elicits negative affect (Rothman et al., 2017). This is because relational ambivalence is assumed to lead to conflicting thoughts and aversive feelings (van Harreveld et al., 2015) that interfere with followers' capacity to perform well in their jobs (e.g., Koy \& Yeo, 2008).

Therefore, by examining the effects of LMX ambivalence in the current research, we aim to substantially extend our knowledge of leader-follower relationships and LMX theory. We expect that high LMX ambivalence will be negatively associated with task performance and that this effect will be independent of LMX quality. Our second novel aim is to examine an important way that interpersonal relationships can influence the effects of workplace ambivalence (i.e., their ambivalence-buffering function). Guided by the cross-domain buffering hypothesis (Duffy, Ganster, \& Pagon, 2002), we argue that relationships outside of the leaderfollower domain, namely, perceived organizational support (POS) and coworker support (CWS), provide an important source of support for the follower that can help nullify the negative impact of LMX ambivalence on task performance. Our final aim is to uncover the underlying process that links LMX ambivalence to task performance. Informed by ambivalence research, we propose that negative affect will mediate the negative relationship between LMX ambivalence and task performance such that this indirect effect is nullified when either POS or CWS are high. A visual representation of this model can be seen in Figure 1.

Our research makes three main theoretical contributions to the literature. First, by exploring LMX ambivalence, we contribute to the growing body of work on ambivalence at work by expanding the foci of ambivalence from the organization (e.g., organizational identification) and the job (e.g., job attitudes) to a novel and important target: the leader-follower relationship. In doing so, we can also better account for arguably the most important (theoretically and practically) work outcome, namely, employee performance. To date, few studies have researched the link between ambivalence and task performance (e.g., Pratt, 2000ambivalent organizational identification and sales performance); therefore, by demonstrating the performance implications of LMX ambivalence (beyond those of LMX quality), we aim to make a critical contribution to this embryonic literature. Furthermore, we address the call to extend our knowledge of how actors deal with ambivalence (Ashforth et al., 2014) and, in particular, the moderators that explain when different outcomes of ambivalence arise (Rothman et al., 2017). We draw from the broader literatures on attitudinal and relational ambivalence to test a model exploring when and how employees respond to LMX ambivalence. Accordingly, we aim to show how workplace relationships can both elicit and alleviate ambivalence and, in particular, the value of external (i.e., POS and CWS) support for buffering the detrimental effects of LMX ambivalence.

Second, by developing and testing a new construct, LMX ambivalence, that is distinct from LMX quality, we extend and broaden the conceptualization and understanding of LMX relationships. In doing this, we contribute to the body of recent research that has recognized additional dimensions beyond relationship quality in order to provide a more theoretically 
Figure 1

Visual Representation of the Theoretical Model Proposed in Study 1 and Study 2

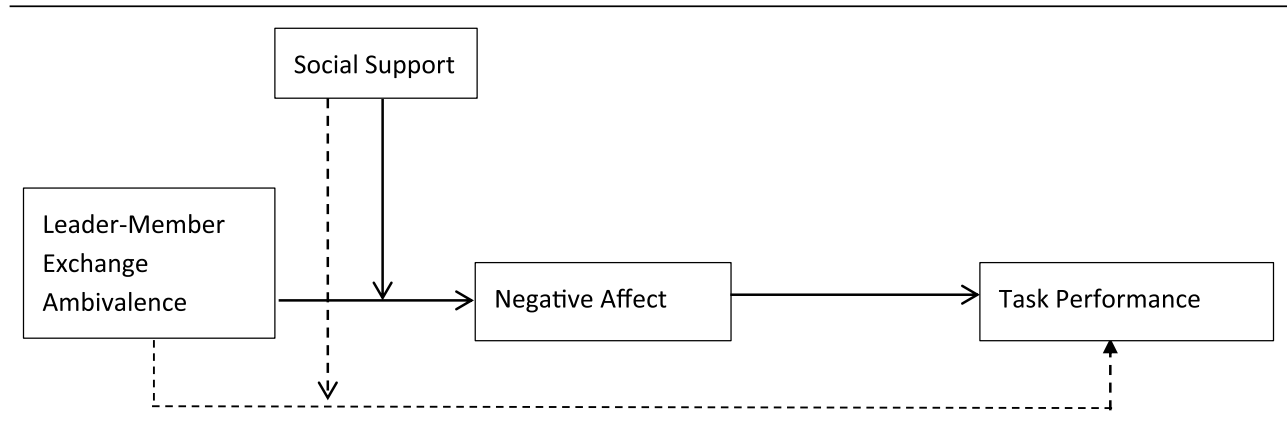

Note: Relationships examined in Study 1 are represented with dashed lines; social support was operationalized as perceived organizational support. Relationships examined in Study 2 are represented with solid lines; social support was operationalized as coworker support.

complete understanding of the leader-follower relationship (e.g., Lee, Martin, Thomas, Guillaume, \& Maio, 2015; Vidyarthi, Liden, Anand, Erdogan, \& Ghosh, 2010). Recent advances in LMX theory have shown that there is considerable variation in relationship quality between leader-follower dyads in the same work group (i.e., LMX differentiation; Henderson, Liden, Glibkowski, \& Chaudhry, 2009) because leaders treat their followers differently. In this paper, we extend this notion of within-group LMX inconsistency and show that within leader-follower dyads, there may also be inconsistent and conflicting thoughts about the relationship.

Finally, we extend LMX theory by testing a theoretical model explaining when and how LMX ambivalence predicts task performance. The performance implications of LMX quality are central to LMX theory (see Martin, Guillaume, Thomas, Lee, \& Epitropaki, 2016). By proposing a moderated mediation model predicting the LMX ambivalence-performance link, the mediating role of negative affect, and the moderating role of social support, we seek to show that there are important facets of the LMX relationship (in addition to LMX quality) that influence task performance.

\section{Theoretical Background and Hypotheses Development}

\section{LMX Theory}

As noted earlier, we aim to extend the typical target of ambivalence from the organization (e.g., Schuh, Van Quaquebeke, Göritz, Xin, De Cremer, \& van Dick, 2016) to a pivotal context - the leader-follower relationship (Sparrowe \& Liden, 2005). The LMX relationship not only is a key determinant of employee behavior (e.g., Dulebohn, Bommer, Liden, Brouer, \& Ferris, 2012) but also colors followers' perceptions of the leader and the organization more generally (Martin, Epitropaki, Thomas, \& Topakas, 2010). There is good evidence, for example, that the LMX relationship is a more proximal determinant of employee behavior than measures of leadership style. For instance, LMX quality mediates the link between transformational (e.g., Wang, Law, Hackett, Wang, \& Chen, 2005) and servant (e.g., Newman, 
Schwarz, Cooper, \& Sendjaya, 2017) leadership styles and employee behavior. Similarly, LMX quality has been shown to mediate the relationship between followers' identification with their leader and their subsequent behavior (Gu, Tang, \& Jiang, 2015). Thus, LMX quality is highly salient and influential to followers.

The most prominent theory of relational leadership is LMX theory (Uhl-Bien, 2006). The central principle of LMX theory is that through different kinds of exchanges, leaders differentiate the way they treat their followers (Dansereau et al., 1975), leading to different quality relationships between the leader and each follower. As previously discussed, LMX researchers have examined the leader-follower relationship from a univalent perspective, implicitly assuming that such relationships are characterized as either primarily high quality or primarily low quality (Lian, Ferris, \& Brown, 2012). Thus, research has ignored the possibility that followers may perceive the relationship to be both high and low quality. Research on ambivalence, however, has demonstrated that the negative and positive aspects of a relationship typically form related but distinct factors and, as such, do not merely represent opposite endpoints on a continuum (Baumeister, Bratslavsky, Finkenauer, \& Vohs, 2001). Accordingly, followers may have conflicting perceptions about their LMX relationship. In the current study, we characterize this as LMX ambivalence - the coexistence of positive (i.e., highquality) and negative (i.e., low-quality) cognitions regarding the LMX relationship. Below, we introduce the concept of ambivalence within leader-follower relationships.

\section{LMX: A Relational Ambivalence Perspective}

The concept of ambivalence permeates the literature related to social psychology (e.g., van Harreveld et al., 2015), political science (e.g., Huckfeldt, Mendez, \& Osborn, 2004), and sociology (e.g., Mulligan, 2015). Research into ambivalence stems from the observation that bipolar measures of attitudes (such as a semantic differential ranging from "bad" to "good") fail to separate ambivalence and indifference. In such cases, an individual will most likely check the midpoint of the bipolar scale (Klopfer \& Madden, 1980), even though these two evaluations are profoundly different. Individuals who are indifferent, for instance, have weak positive and negative evaluations, whereas those who are ambivalent have strong positive and negative evaluations (e.g., Methot, Melwani, \& Rothman, 2017; Priester \& Petty, 1996).

Scholars have recognized and studied different forms of ambivalence, including attitudinal ambivalence, relational ambivalence, emotional ambivalence, trait ambivalence, and expressed ambivalence (see Rothman et al., 2017, for a review). These forms define ambivalence in different ways but emphasize the simultaneous existence of strong, polar opposite thoughts or feelings towards a given entity. In the current research, we draw specifically on research and theory related to relational and attitudinal ambivalence, focusing on ambivalent cognitions (i.e., attitudes) towards one's LMX relationship. It is also important to distinguish between objective and subjective ambivalence (van Harreveld et al., 2015). Objective ambivalence refers to the existence of conflicting associations about an attitude object, whereas subjective (or felt) ambivalence refers to the (meta) experience of this conflict (Bassili, 1996; Thompson, Zanna, \& Griffin, 1995). The current research focuses on subjective ambivalence because it represents a salient and more intense form of ambivalence (see Ashforth et al., 2014). By definition, individuals are aware of subjective ambivalence, which may not be the case for objective ambivalence (e.g., Costarelli \& Colloca, 2004). As such, objective 
ambivalence has the potential to be low intensity and, therefore, likely to be ignored and have little impact on behavior (Ashforth et al., 2014).

As indicated previously, existing perspectives on workplace relationships routinely characterize them as unidimensional, positioning them along a bipolar continuum from negative to positive (Methot et al., 2017). The same is true of LMX relationships, which are posited to exist on a continuum between low and high quality. However, research demonstrates that many individuals construe their relationships as having a mix of positive and negative evaluations (e.g., Petty \& Cacioppo, 1996) and that such perceptions can exist within all types of relationships: for example, relationships with spouses (e.g., Uchino, Smith, \& Berg, 2014), friends (e.g., Holt-Lunstad, Uchino, Smith, \& Hicks, 2007), and coworkers (Pratt \& Doucet, 2000). As evidence, it has been found that LMX quality and abusive supervision are distinguishable constructs (Burris, Detert, \& Chiaburu, 2008), indicating that abusive supervision can occur within both low- and high-quality LMX relationships.

Ambivalent relationships are common in people's social networks. For example, research suggests that around $50 \%$ of the important ties in an individual's social network are ambivalent (Campo, Uchino, Holt-Lunstad, Vaughn, Reblin, \& Smith, 2009). Researchers investigating relational ambivalence argue for an extended typology of interpersonal relationships that includes aversive, supportive, indifferent, and ambivalent ties (e.g., Bushman \& HoltLunstad, 2009). Examining ambivalence within the leader-follower relationship is particularly relevant because rather than focusing purely on the behavioral styles or traits of a leader, relational approaches, such as LMX, highlight that the relationship is dyadic in nature and mutually influenced. This is a vital distinction when researching ambivalence as it suggests that ambivalence will be influenced by the characteristics of the leader, the follower, and the leader-follower relationship. This distinction fits well with the literature on ambivalence, which has shown, for example, that individual and dyadic attachment styles can predict the development of ambivalent relationships (Mikulincer, Shaver, Bar-On, \& Ein-Dor, 2010).

Importantly, a good deal of research has explored ambivalence in the context of interpersonal relationships outside of the workplace (e.g., Uchino et al., 2014), and this provides a good basis for theoretical integration with LMX theory. Furthermore, the nature of the relationship between leaders and their followers has the potential to lead to significant levels of ambivalence for several reasons. First, findings from the interpersonal relationships literature suggest that dyadic ambivalence increases under conditions of dependence (e.g., Fingerman, Pitzer, Lefkowitz, Birditt, \& Mroczek, 2008). LMX quality is often characterized by dependence and loyalty as leaders may be vital for career progression and hold valuable resources. Leaders, for example, are a source of reward and punishment, including the provision of basic human needs such as self-esteem, affection, and reinforcement as a member of a group (see De Dreu, West, Fisher, \& MacCurtain, 2001). Followers, on the other hand, have less power in the relationship, and this imbalance may create friction between dependence and the need for autonomy, which in turn can lead to ambivalent relationship cognitions (Fingerman, 2001). Indeed, this may represent an "organizational duality" (Ashforth et al., 2014) whereby a follower may accept dependence on the leader in order to act independently.

Second, leaders and followers typically have to fulfil multiple organizational roles within the dyad, including supervisor, subordinate, coworker, and friend. Developing and maintaining such relationships requires individuals to balance professional norms of impartiality, confidentiality, and evaluation with personal norms of favoritism, openness, and acceptance 
(Methot et al., 2017). This creates opportunities for the development of relational ambivalence as a result of the potential for conflicts to arise from the need to adopt different roles at different times. Indeed, relationships within organizations are often multifaceted and/or multiplex, involving different relationship types, such as personal and professional (Ashforth et al., 2014; Rothman et al., 2017). To illustrate, Pratt and colleagues' research demonstrated that employees expressed ambivalence towards authority because managers placed conflicting demands on workers but were also sources of emotional support (Pratt, 2000; Pratt \& Doucet, 2000). Furthermore, the more familiar an actor is with an object, the greater the likelihood of having encountered the object's multiple facets and imperfections (Ashforth et al., 2014). Thus, in the case of leader-follower relationships, the closeness of the relationship is especially likely to breed ambivalence in the same way that even robust mentor-protégé relationships are inherently ambivalent (Oglensky, 2008).

Finally, scholars have suggested that individuals are more likely to maintain ambivalent relationships as a result of the real or perceived barriers that hold such relationships together (Bushman \& Holt-Lunstad, 2009). These barriers may be external (e.g., a lack of an alternative), internal (e.g., commitment to the relationship), or both and can exert real or imagined pressure on individuals to continue a relationship. Because of the involuntary nature of leader-follower relationships, employees are likely to perceive strong external barriers to exiting highly ambivalent leader-follower relationships. Such barriers might result in pressure on followers to maintain a relationship despite the interpersonal stress associated with it. This line of argument is consistent with previous research showing that individuals can indefinitely maintain a state of relational ambivalence (Thompson \& Holmes, 1996).

Thus, LMX relationships may be characterized as ambivalent, which leads to the following question: What effect does LMX ambivalence have on important employee outcomes?

\section{LMX Ambivalence and Task Performance}

Employee performance is one of the most researched outcomes in relation to LMX quality. A recent meta-analysis found 146 samples examining the association between LMX quality and task performance (Martin et al., 2016). This focus is unsurprising given the contribution employee performance makes to the accomplishment of organizational goals (e.g., Rotundo \& Sackett, 2002). Meta-analytic evidence shows that LMX quality is positively associated with self-rated, other-rated, and objective task performance (Martin et al., 2016). However, the effect of LMX ambivalence on performance is unknown. At face value, it could be argued that high LMX ambivalence would have a muted or neutral effect on performance, falling somewhere between the effects of low- and high-quality LMX relationships. However, research on ambivalence suggests that having conflicted evaluations represents a state of mind very different from neutrality or indifference. Thus, we suggest that LMX ambivalence will have unique effects on task performance beyond those of overall LMX quality.

Despite the burgeoning interest in ambivalence within the management literature (Rothman et al., 2017), surprisingly few studies have directly examined the effect of ambivalence on performance. Pratt (2000) demonstrated that ambivalent organizational identification was associated with lower sales performance. However, research by Ingram and colleagues (e.g., Ingram \& Roberts, 2000; Zou \& Ingram, 2013) has revealed the performance benefits of having competitive friendships. Although ambivalence was not directly measured in these studies, friendship among competitors could be construed as a multiplex 
relationship that arguably may elicit ambivalence. Nevertheless, the aforementioned studies provide a limited basis for predicting the effects of LMX ambivalence on performance. Thus, to understand the nature of the LMX ambivalence-performance relationship, we draw primarily upon the broader ambivalence literature.

On the basis of a recent review by Rothman et al. (2017) of why and when ambivalence elicits positive and negative outcomes, there are good reasons to expect that LMX ambivalence will have a negative effect on performance. First, the downside of ambivalence has been associated with cognitive (rather than emotional) ambivalence (Rothman et al., 2017), and the defining feature of LMX ambivalence is the experience of conflicting cognitions (as opposed to conflicting emotions). Second, the experience of ambivalence is detrimental to the extent that it elicits negative affective responses. Research from the psychology domain suggests that ambivalence violates the need for consistency (Festinger, 1957) and, thus, is generally described as uncomfortable or even agonizing (Pratt, 2000) to the extent that individuals need to dedicate psychological resources towards coping with this aversive experience (Ashforth et al., 2014). The aversive nature of LMX ambivalence is therefore likely to have a detrimental effect on performance due to the creation of off-task attentional demands that will detract from the cognitive and emotional energies necessary for performance-related tasks (e.g., Koy \& Yeo, 2008). Third, ambivalence-induced negative affect is more likely to follow from substantive (i.e., high intensity) rather than superficial (i.e., low intensity) ambivalence (Ashforth et al., 2014). As LMX ambivalence reflects subjective ambivalence towards the leader-follower relationship, higher levels of LMX ambivalence represent a more intense experience that is more likely to elicit negative consequences. Finally, in terms of the target of ambivalence, ambivalence towards relationships (as opposed to ideas) generally has negative consequences (Pratt \& Pradies, 2011). Relationships are characterized by a large investment of the self; thus, ambivalent relationships are likely to engender hot cognition that leads to dysfunctional outcomes (Pratt \& Pradies, 2011). Indeed, ambivalent relationships may even be more detrimental to outcomes than simple negative relationships (Holt-Lunstad et al., 2007; Rothman et al., 2017). Thus, on the basis of the reasoning above, we expect that high LMX ambivalence is likely to have a deleterious effect on task performance. This leads to the following hypothesis:

Hypothesis 1: LMX ambivalence will be negatively associated with task performance.

\section{LMX Ambivalence and Performance: Cross-Domain Buffering}

Research related to ambivalence has paid relatively little attention to how employees deal with ambivalence and, in particular, the contextual factors that might moderate its effects. Recently, Methot and colleagues (2017) suggested that a key area for future research is the exploration of boundary conditions that might mitigate or exacerbate the links between ambivalent relationships and work outcomes. Previous studies have shown social support can mitigate the negative effects of a number of different stressors (e.g., van Emmerik, Euwema, $\&$ Bakker, 2007). This process is known as the buffering hypothesis of social support (Sarafino, 1997). Key sources of social support in the workplace include coworkers, leaders, and the organization itself. According to the cross-domain buffering hypothesis of social support (e.g., Duffy et al., 2002), social support from a different domain (e.g., coworker or organizational support) should be particularly effective at reducing the negative consequences of a stressor from another domain (i.e., an ambivalent LMX relationship). For instance, Hobman, Restubog, 
Bordia, and Tang (2009) demonstrated that in the presence of high team-member support, there was a negligible association between abusive supervision and employees' well-being and job satisfaction. While LMX ambivalence is not the same as abusive supervision, we expect that social support from sources external to the leader-follower relationship can buffer the negative effects of LMX ambivalence on employee performance.

In Study 1, we draw on this cross-domain buffering hypothesis to suggest that POS will reduce aversive psychological reactions to LMX ambivalence by indicating the availability of material and emotional support when needed (Rhoades \& Eisenberger, 2002). POS is defined as the extent to which employees perceive that their contributions are valued by their organization and that the organization cares about their well-being (e.g., Rhoades \& Eisenberger, 2002). POS has been shown to be negatively associated with strains experienced in the workplace and positively associated with job-related affect (e.g., job satisfaction and mood) by reducing negative reactions to stressors (Eisenberger, Armeli, Rexwinkel, Lynch, \& Rhoades, 2001). Accordingly, we propose the following hypothesis:

Hypothesis 2: The relationship between LMX ambivalence and task performance will be moderated by POS such that the negative effect will be reduced when POS is high.

\section{Study 1}

The aims of this field study are threefold. First, we aim to demonstrate that our new measure of LMX ambivalence (which we develop in the online supplemental material) has predictive validity beyond that of the measure of the overall quality of the LMX relationship. Second, we aim to examine the effects of LMX ambivalence on task performance (Hypothesis 1). Finally, we aim to investigate the moderating role of POS to ascertain whether this acts as a buffer to the negative effects of LMX ambivalence on performance (Hypothesis 2).

\section{Method}

\section{Sample}

We collected data from three organizations, two based in the United Kingdom and one based in India. These organizations were approached directly by the lead researcher and asked whether they would like to participate in the project. Participants in all three organizations worked in a service center environment providing telephone support or telephone sales, that is, customer service support, outsourced human resources (HR) services, and outsourced business processes. Our final sample consisted of 320 employees nested within 60 teams, representing a response rate of $84 \%$. The teams shared a single supervisor; however, team members largely worked independently of one another. The average age of the combined sample was 28 years, and $60 \%$ of respondents were male. The average organizational tenure was 23 months.

\section{Procedure}

After the organizations agreed to participate, links to the online survey were sent to a representative of the HR departments in the three organizations. These representatives then 
sent the survey links to the staff of the organization. After giving informed consent, participants completed the short online survey, which took approximately 10 to 15 minutes. To deal with the potential problems associated with single-informant bias, we separated the measurement of the independent and dependent variables and collected data through multiple respondents. Accordingly, we concurrently collected measures of LMX quality, LMX ambivalence, and POS from employees and task performance from supervisors. Supervisors provided the names and performance ratings of each of their followers. Followers were required to provide their names on their survey in order for the data to be matched. However, only the researchers had access to the matched data, and these data were kept confidential from the respondents.

\section{Measures}

The participants responded to items on a 5-point Likert-type scale $(1=$ strongly disagree to $5=$ strongly agree). Higher scores indicated higher levels of the underlying construct.

LMX ambivalence. Because no previous studies have measured LMX ambivalence, we developed a new scale by adapting Graen and Uhl-Bien's (1995) scale to examine the degree to which an individual had conflicting thoughts about their LMX relationship (see the online supplemental material for the scale validation procedure and full list of scale items). We measured LMX ambivalence subjectively by directly asking respondents to indicate the degree to which they experienced ambivalent cognitions about their leader-follower relationship $(\alpha=.92)$. An example item was "I have conflicting thoughts: sometimes I think that my working relationship with my manager is very good, while at other times, I don't."

POS. We measured POS using six items (Eisenberger et al., 2001; $\alpha=.76$ ). An example item was "The organization takes pride in my accomplishments."

Task performance. We assessed followers' task performance from their immediate supervisor using four items (Nahrgang, Morgeson, \& Ilies, 2009; $\alpha=.95$ ). An example item was "This team member's performance is very high."

Controls. We controlled for LMX quality in order to determine the independent effect of LMX ambivalence on performance beyond that explained by the overall quality of the relationship. LMX quality was measured using a seven-item measure (LMX7; Graen \& UhlBien, 1995; $\alpha=.84)$. It could be argued that LMX ambivalence reflects moderate levels of LMX quality. In other words, there may be a curvilinear effect between LMX quality and LMX ambivalence that would not be detected in the correlations or confirmatory factor analysis (CFA). To control for any curvilinear effects of LMX, we created a new variable, LMX squared, where the grand mean centered LMX scale was multiplied by itself (i.e., LMX $\times$ LMX; Cohen, Cohen, West, \& Aiken, 2003). Additionally, we controlled for a number of demographic variables (i.e., age, gender, and dyadic tenure) because they have been shown to affect contextual and task performance (e.g., Green, Jegadeesh, \& Tang, 2009; Ng \& Feldman, 2010; Sturman, 2003). Furthermore, because the data were collected in three different organizations, we controlled for organizational membership (dummy coded). 


\section{Table 1}

Means, Standard Deviations, Correlations, and Internal Consistencies of the Variables Used in Study 1

\begin{tabular}{|c|c|c|c|c|c|c|c|c|c|c|}
\hline Variables & 1 & 2 & 3 & 4 & 5 & 6 & 7 & 8 & $M$ & $S D$ \\
\hline 1. LMX Quality & $(.84)$ & & & & & & & & 3.93 & 0.57 \\
\hline 2. LMX Ambivalence & $-.25 * *$ & $(.92)$ & & & & & & & 2.90 & 0.89 \\
\hline 3. Perceived Organizational Support & $.40 * *$ & $-.25 * *$ & $(.76)$ & & & & & & 3.43 & 0.63 \\
\hline 4. Task Performance & $.34 * *$ & $-.26 * *$ & $.30 * *$ & $(.95)$ & & & & & 3.98 & 0.89 \\
\hline 5. Organization 1 & -.03 & $-.12 *$ & $-.21 * *$ & -.06 & & & & & & \\
\hline 6. Organization 2 & .05 & -.09 & .03 & -.05 & -.10 & & & & & \\
\hline 7. Gender ${ }^{\mathrm{a}}$ & .05 & -.04 & .01 & .02 & .05 & -.03 & & & 0.37 & 0.48 \\
\hline 8. Age & -.03 & -.01 & $.11^{*}$ & .06 & $-.17 * *$ & $.23 * *$ & -.02 & & 28.30 & 7.59 \\
\hline 9. Dyadic Tenure ${ }^{b}$ & .03 & .01 & .09 & -.02 & $-.19 * *$ & $.37 * *$ & -.06 & $.37 * *$ & 22.98 & 32.13 \\
\hline
\end{tabular}

Note: $N=320$. Performance rated by leaders; all other variables are follower rated. Values in parentheses indicate Cronbach alphas. LMX = leader-member exchange.

${ }^{\mathrm{a}} 1=$ Female, $0=$ Male.

bMonths.

$* p<.05$.

$* * p<.01$.

\section{Results}

Table 1 presents the means, standard deviations, and zero-order correlations among the study variables. All the variables had good reliability. In accordance with Hypothesis 1, the correlation between LMX ambivalence and task performance was significant and negative ( $r$ $=-.26$ ). Furthermore, the correlation between LMX ambivalence and LMX quality was modest $(r=-.25)$.

\section{Discriminant Validity}

In the online supplemental material, we demonstrate the validation of the LMX ambivalence scale using a rigorous methodology involving additional data sets. In the current study, we conducted CFAs using MPLUS (Version 6) to examine further the distinctiveness of the LMX quality and LMX ambivalence constructs (as well as the other variables included in this study). Accordingly, we compared the model fit of the full measurement model, where LMX ambivalence, LMX quality, POS, and task performance were included as separate factors, to a series of models where scales were combined in various combinations. The model that allowed the various items to load onto their respective factors produced a good model fit $\left(\chi^{2}=525.01, d f=246, p<.001\right.$; comparative fit index $(\mathrm{CFI})=.94$; Tucker-Lewis index $(\mathrm{TLI})=.93$; root mean square error of approximation $($ RMSEA $)=.06)$ and one that was better than any model in which scales were combined. For instance, the model where LMX ambivalence and LMX quality were combined into one factor produced a significantly worse model fit $\left(\chi^{2}=1,179.45, d f=249, p<.001 ;\right.$ CFI $=.80 ;$ TLI $=.78$; RMSEA $=$ $.11)$ as did a model with all items combined into a single factor $\left(\chi^{2}=3,055.93, d f=252\right.$, 
$p<.001 ; \mathrm{CFI}=.39 ; \mathrm{TLI}=.33$; RMSEA $=.19)$. This was confirmed using chi-squared difference tests, which were all significant (e.g., for the one-factor model, $\Delta \chi^{2}=2,530.92, \Delta d f$ $=6, p<.001)$. Thus, the results added further support for the discriminant validity of the focal variable in this study.

\section{Hypothesis Testing}

The participants consisted of individuals nested within teams ( $N=60$ teams); thus, there was the potential that uncorrected tests of individual-level relationships may have inadvertently contained team-level effects (e.g., Bauer, Preacher, \& Gil, 2006). To assess this, we calculated the intraclass correlation coefficient, or ICC(1), which indexes the amount of variance in a given variable that can be attributed to team membership. The ICC(1) value of .08 for task performance (Bliese, 1998) indicated that a small portion of the variance in the ratings of employees' task performance could be accounted for by team membership. Accordingly, we tested our hypotheses by using a multilevel model that included both the individual (follower) level and the team level (see Table 2). In these analyses, we did not aggregate variables to the team level but, rather, analyzed data on an individual level using a method that simultaneously took account of the variation between individuals and between teams.

We tested the random coefficient models using multilevel regression analysis, employing SPSS (Version 23) software and using its mixed analysis function. In the first step, we tested a null model in order to examine the percentage of variance residing at each of the two levels (individual and team). Specifically, for Model A, we calculated an empty model in which we allowed the intercept to vary across both individual and team levels. In Model B, we entered our control variables. We then entered the predictor variable, LMX ambivalence (Model C), then added the moderator variable, POS (Model D), and then added the interaction term (Model E); these variables were grand-mean centered prior to inclusion. The results of each model are shown in Table 2 and provide support for Hypothesis 1, showing that LMX ambivalence had a significant negative relationship with task performance $(\beta=-0.19, t(309)=$ $-3.32, p<.001$; Model D).

As shown in Table 2, the interactive effect of LMX ambivalence and POS on task performance was significant $(\beta=0.17, t(308)=2.22, p=.027)$. In order to explore the nature of this significant interaction, we reviewed the conditional effects at two levels (1 SD above and $1 S D$ below the mean) of the moderator (POS; see Figure 2). We found that the relation between LMX ambivalence and performance was significant and negative when POS was low $(\beta=-0.31, t(308)=-3.96, p<.001)$ but was nonsignificant when POS was high $(\beta=$ $-0.10, t(308)=-1.49, p=.138)$. We therefore found support for Hypothesis 2 by showing that high levels of POS ameliorated the negative effect of LMX ambivalence on task performance.

\section{Discussion}

In Study 1, we provided an examination of the LMX ambivalence construct and found it to be distinct from overall LMX quality. In accordance with ambivalence research, our evidence showed that ambivalent cognitions about the leader-follower relationship were associated with poorer task performance. Furthermore, high levels of POS nullified this negative 


\section{Table 2}

Multilevel Moderated Regression Analysis Results for Interactions Between LeaderMember Exchange and Perceived Organizational Support in Study 1

\begin{tabular}{|c|c|c|c|c|c|}
\hline & Model A & Model B & Model C & Model D & Model E \\
\hline & $\beta(S E) t$ & $\beta(S E) t$ & $\beta(S E) t$ & $\beta(S E) t$ & $\beta(S E) t$ \\
\hline Intercept & $3.99(0.06) 66.61 * *$ & $1.72(0.45) 3.86^{* *}$ & $2.29(0.45) 5.10 * *$ & $2.59(0.47) 5.56^{* *}$ & $2.61(0.46) 5.63^{* *}$ \\
\hline Organization 1 & & $-0.12(0.13)-0.92$ & $-0.16(0.12)-1.35$ & $-0.10(0.12)-0.79$ & $-0.09(0.12)-0.78$ \\
\hline Organization 2 & & $-0.39(0.26)-1.47$ & $-0.48(0.25)-1.91$ & $-0.45(0.25)-1.77$ & $-0.46(0.25)-1.84$ \\
\hline Age & & $0.01(0.01) 1.53$ & $0.01(0.00) 1.32$ & $0.01(0.01) 1.11$ & $0.01(0.01) 1.14$ \\
\hline Gender $^{\mathrm{a}}$ & & $-0.00(0.10)-0.03$ & $0.01(0.10) 0.09$ & $0.01(0.10) 0.07$ & $0.01(0.09) 0.08$ \\
\hline Dyadic Tenure & & $-0.00(0.00)-0.63$ & $-0.00(0.00)-0.41$ & $-0.00(0.00)-0.48$ & $-0.00(0.00)-0.46$ \\
\hline LMX & & $0.52(0.09) 5.54 * *$ & $0.39(0.10) 4.10^{* *}$ & $0.32(0.10) 3.22 * *$ & $0.32(0.10) 3.25^{* *}$ \\
\hline LMX $\times$ LMX & & $-0.03(0.09)-0.39$ & $-0.12(0.08)-1.45$ & $-0.11(0.08)-1.34$ & $-0.11(0.08)-1.33$ \\
\hline LMX Ambivalence & & & $-0.22(0.06)-3.94 * *$ & $-0.19(0.06)-3.32 * *$ & $-0.21(0.06)-3.59 * *$ \\
\hline POS & & & & $0.20(0.08) 2.45^{*}$ & $0.23(0.08) 2.71^{* *}$ \\
\hline $\begin{array}{l}\text { LMX Ambivalence } \\
\times \text { POS }\end{array}$ & & & & & $0.17(0.08) 2.22^{*}$ \\
\hline
\end{tabular}

Note: $N=320$. Estimation method $=$ restricted maximum likelihood. LMX $=$ leader-member exchange; POS $=$ perceived organizational support.

a $1=$ Female, $0=$ Male.

$* p<.05$.

$* * p<.01$.

Figure 2

Task Performance as a Function of Leader-Member Exchange Ambivalence for High $(+1 S D)$ and Low (-1 SD) Perceived Organizational Support for Study 1

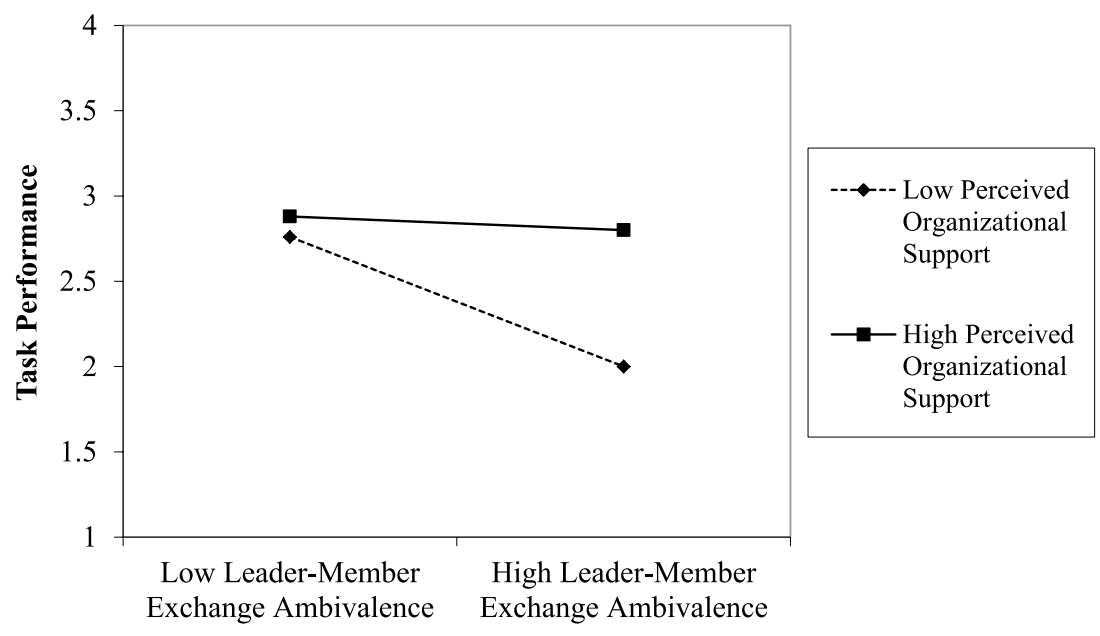

relationship between LMX ambivalence and task performance, supporting our cross-domain buffering hypothesis (Duffy et al., 2002). Thus, feeling supported by one's organization can act as a buffer against the detrimental effects of LMX ambivalence. Importantly, these effects were shown when controlling for LMX and the quadratic term of LMX, suggesting 
that LMX ambivalence has effects beyond those of LMX quality and the curvilinear effects of LMX.

Despite the support for our hypotheses, Study 1 had several limitations that need to be addressed to provide greater confidence and understanding regarding the effects of LMX ambivalence. First, we focused on the main effect between LMX ambivalence and task performance. Although we provided a theoretical rationale for this effect, we did not test any underlying mechanisms that may explain it. Thus, in Study 2, we build on these findings by examining the role of negative affect as a potential mechanism through which the effect occurs. Second, we explored one source of social support (external to the leader-follower relationship) in the workplace, namely, POS. Hence, in Study 2, we further explore the boundary conditions of LMX ambivalence by examining the role of CWS as a buffer to the negative effects of LMX ambivalence. Finally, we relied on a cross-sectional research design in which all of our data were collected at the same time point. Thus, in Study 2, we employ a more robust study design where data were time separated, allowing us to explore the influence of LMX ambivalence on subsequent performance (compared to baseline performance levels) while controlling for LMX quality.

\section{Study 2}

In Study 2, we aim to add further credence to the notion that ambivalent cognition about one's leader-follower relationship is an important extension to LMX theory that furthers our understanding of how and when LMX relationships influence task performance. In doing so, we build on Study 1 by testing an extended model that incorporates a theoretically guided mediator and an alternative moderator that may better explain the link between LMX ambivalence and task performance.

\section{LMX Ambivalence and Negative Affect}

As highlighted by Rothman and colleagues, "The types of negative outcomes of ambivalence that have been studied in psychology largely build on the assumption that negative affect is the driving mechanism" (2017: 39). However, while negative affect is central to explaining the negative effects of ambivalence, few studies have empirically tested it as an outcome of ambivalence (e.g., Newby-Clark, McGregor, \& Zanna, 2002; Nordgren, van Harreveld, \& van der Pligt, 2006). Within the workplace context, little is known about the emotional consequences of cognitive ambivalence and whether negative emotional responses can explain the detrimental effects on employee behavior. Recently, Methot and colleagues (2017) proposed that more research should aim to develop and empirically test models where ambivalent relationships predict proximal emotions, which in turn predict work attitudes and behaviors. Accordingly, we argue that the effects of LMX ambivalence can be explained by the notion of ambivalence-induced negative affect (van Harreveld et al., 2015), which suggests that holding contrasting cognitions about the same object is aversive because it violates fundamental consistency motives (Festinger, 1957).

Hypothesis 3: LMX ambivalence will be positively associated with the experience of negative affect. 


\section{Negative Affect and Task Performance}

Following the preceding conceptualization of LMX ambivalence as a stressor, we argue that LMX ambivalence will elicit an emotional reaction in the form of negative affect. Resource allocation theories highlight that individuals have a limited amount of attentional resources available and that performance will be diminished if cognitive and emotional energies are directed away from task performance (e.g., Koy \& Yeo, 2008). Accordingly, individuals dealing with high environmental demands (e.g., high LMX ambivalence and associated negative affect) dissipate valuable resources (e.g., energy, cognitive focus, emotional stability) in order to cope with such demands (Sguera, Bagozzi, Huy, Boss, \& Boss, 2016). This contention is supported by research showing that negative affect creates off-task attentional demands (e.g., Koy \& Yeo, 2008) such as self-focused attention (Mor \& Winquist, 2002), rumination (Feldner, Leen-Feldner, Zvolensky, \& Lejuez, 2006), appraisal, and arousal (Beal, Weiss, Barros, \& MacDermid, 2005). Moreover, attempts to regulate negative affective experiences may serve to exacerbate the situation by further reducing the attentional resources available for task performance (e.g., Beal et al., 2005). Thus, we predict that the negative affect associated with LMX ambivalence will have a deleterious effect on task performance. Furthermore, on the basis of the aforementioned theory and research, we argue for a negative relationship between LMX ambivalence and task performance mediated by negative affect.

Hypothesis 4: Negative affect will mediate the relationship between LMX ambivalence and task performance.

\section{LMX Ambivalence and Negative Affect: The Moderating Role of CWS}

In Study 1, we found support for our hypothesis that perceived support from one domain (i.e., the organization) mitigates the negative consequences of a stressor in another domain (i.e., the leader). To extend the findings of Study 1, we further explore this cross-domain buffering hypothesis by examining another important and proximal source of support to employees in the workplace: CWS. CWS refers to the extent to which employees believe that their coworkers are willing to provide them with work-related support and assistance at work (Susskind, Kacmar, \& Borchgrevink, 2003); as such, it represents an important source of social support (e.g., Halbesleben, Neveu, Paustian-Underdahl, \& Westman, 2014). Relatedly, CWS has been found to buffer the negative relationship between employee outcomes and both supervisor undermining (Duffy et al., 2002) and abusive supervision (Hobman et al., 2009). Moreover, coworkers share the same leader and, hence, are well placed to provide support, such as information and empathy, and can act as a sounding board for discussing and alleviating feelings of uncertainty and tension that LMX ambivalence engenders (Balkundi \& Harrison, 2006). In other words, coworkers are a key source of support for coping with the demands of the workplace. Taken together, we predict that like POS, CWS will mitigate the negative effect of having ambivalent cognitions regarding the leader-follower relationship.

Hypothesis 5: CWS will moderate the strength of the mediated relationship between LMX ambivalence and task performance via negative affect, such that the mediated relationship will be weaker when CWS is high compared to when it is low. 


\section{Method}

\section{Procedure}

To test Hypotheses 3 through 5, we collected data from project teams consisting of four to five students engaged in a business strategy module as part of their degree course. The module, which ran for 24 weeks, involved teams working on the design and manufacture of a car within a simulated environment. The module was designed to model the organizational context, and each team had a leader (called the managing director, or MD) who was responsible for team formation, development, meetings, and performance. In essence, the teams replicated organizational project teams that work on a shared task for a fixed amount of time. It is noteworthy that the use of student project teams and computer-based simulations to examine propositions related to leadership and other organizational processes has become increasingly common in organizational research (e.g., Mathieu \& Rapp, 2009; Nahrgang et al., 2009; Palanski \& Yammarino, 2011; Yeow \& Martin, 2013). Hence, the present sample is well suited to the intended objectives of this study.

We collected data at two time points: Time 1 ( 3 weeks into the life cycle of the team) and Time 2 (3 months later). At Time 1, team members completed measures of LMX quality, LMX ambivalence, and CWS. Also at Time 1, the MDs rated the performance of their individual team members. At Time 2, team members rated their feelings of negative and positive affect, while the MDs again rated their team members' task performance. For our analysis, we explored the effect of LMX ambivalence on subsequent performance (at Time 2); however, we controlled for previous performance ratings at Time 1. As noted by Demerouti, Bakker, and Bulters (2004), a time lag of 3 months has the advantage that the occurrence of radical changes in work is relatively unlikely, thus enabling the evaluation of the effects of the more structural and changeable characteristics of work. This time period is also consistent with prior longitudinal research (e.g., Lin \& Leung, 2010), including research on LMX (e.g., Nahrgang et al., 2009).

\section{Sample}

The participants were upper-level undergraduates studying business administration or related degrees (e.g., marketing \& finance) at a business school in the United Kingdom. Their average age was 20 years, and $54 \%$ were male. Team members assigned themselves roles, and one role was the team leader (MD). We matched team members' responses to the surveys with responses from their MDs, providing dyadic data for 272 dyads, within 115 teams.

\section{Measures}

We used the same items and response scale to measure follower ratings of LMX quality (Time 1; $\alpha=.85$ ), LMX ambivalence (Time $1 ; \alpha=.90$ ), and leader-rated task performance (Times 1 and 2; $\alpha=.93$ at Time 1 and .94 at Time 2) as those used in Study 1.

Positive and negative affect. One widely used tool to assess positive and negative affectivity is the Positive and Negative Affect Schedule (PANAS; Watson, Clark, \& Tellegen, 1988), a 20-item self-report measure. Researchers assert that affect is both a trait (dispositional) and 
a state (situational) and can be measured accordingly (Watson \& Clark, 1984; Watson et al., 1988). As we were interested in the association between LMX ambivalence and negative affect, we measured it (at Time 2) as a state and asked participants to rate the items on the basis of how they felt when interacting with their leader during the simulation (see Watson et al., 1988). Such a period of time is in line with other research that has investigated affective responses to leadership. For example, Hoobler and $\mathrm{Hu}$ (2013) used the PANAS with a time frame of "the past few months" for reports of negative affect. We asked participants to indicate the extent to which interactions with their leader produced positive $(\alpha=.90)$ and negative $(\alpha$ $=.89$ ) emotions, such as distress, using a scale ranging from 1 (not at all) to 5 (extremely).

CWS. We measured CWS (at Time 1) using four items developed by Haynes, Wall, Bolden, Stride, and Rick $(1999 ; \alpha=.80)$. An example item was "I can count on my team members to back me up." We measured responses on a 5-point scale $(1=$ strongly disagree to $5=$ strongly agree).

Controls. As in Study 1, we controlled for the age and gender of followers and for LMX quality both as a linear and as a quadratic term (LMX squared) measured at Time 1. Similarly, in order to examine the independent effects of negative affect on performance, we controlled for the effect of positive affect (measured at Time 2). While this is common practice (e.g., Chuang, Judge, \& Liaw, 2012), it seemed particularly important for the current study because LMX ambivalence consists of both positive and negative cognitions about the leader-follower relationship and, thus, can be theoretically linked to positive affect as well as to negative affect. Furthermore, research shows that positive affect is positively associated with task performance (e.g., Tsai, Chen, \& Liu, 2007). Performance at Time 1 was rated by the MDs, and we controlled for it as a baseline measure of performance. This was done in order to test for the effect of LMX ambivalence on subsequent (i.e., Time 2) performance, controlling for previous performance.

\section{Results}

Table 3 reports the item intercorrelations, reliabilities, and descriptive statistics for all the independent and dependent variables used in Study 2. We again found LMX ambivalence to be a reliable construct $(\alpha=.90)$. As predicted, LMX ambivalence was negatively associated with subsequent (i.e., Time 2$)$ leader-rated task performance $(r=-.17)$ and positively associated with negative affect $(r=.29)$; negative affect was also significantly correlated with task performance at Time $2(r=-.21)$.

\section{Discriminant Validity}

As in Study 1, we conducted a series of CFAs to test the discriminant validity between the multi-item variables in this study. We again compared the model fit of the full measurement model, where LMX ambivalence, LMX quality, CWS, negative affect, and task performance were all included as separate factors, to a series of models where scales were combined in various combinations. The model that allowed the various items to load onto their respective factors produced a good model fit $\left(\chi^{2}=911.12, d f=454, p<.001\right.$; CFI $=$ $.90 ;$ TLI $=.89$; RMSEA $=.06)$ that was better than other models in which scales were 
Table 3

Means, Standard Deviations, Correlations, and Internal Consistencies of the Variables Used in Study 2

\begin{tabular}{|c|c|c|c|c|c|c|c|c|c|c|}
\hline Variables & 1 & 2 & 3 & 4 & 5 & 6 & 7 & 8 & $M$ & $S D$ \\
\hline 1. LMX (T1) & $(.85)$ & & & & & & & & 3.88 & 0.60 \\
\hline 2. LMX Ambivalence (T1) & $-.51 * *$ & $(.90)$ & & & & & & & 2.49 & 0.76 \\
\hline 3. Task Performance (T1) & .09 & $-.13 *$ & $(.93)$ & & & & & & 4.10 & 0.76 \\
\hline 4. Task Performance (T2) & .05 & $-.17 * *$ & $.57 * *$ & $(.94)$ & & & & & 4.10 & 0.79 \\
\hline 5. Negative Affect (T2) & $-.19 * *$ & $.29 * *$ & -.09 & $-.21 * *$ & $(.89)$ & & & & 1.71 & 0.66 \\
\hline 6. Positive Affect (T2) & $.52 * *$ & $-.34 * *$ & .09 & $.18 * *$ & $-.32 * *$ & $(.90)$ & & & 3.65 & 0.72 \\
\hline 7. Coworker Support (T1) & $.23 * *$ & $-.37 * *$ & .08 & $.13^{*}$ & $-.26 * *$ & $.20 * *$ & $(.80)$ & & 3.86 & 0.73 \\
\hline 8. Age & .06 & -.05 & $-.13 *$ & -.10 & -.03 & .00 & .03 & & 21.40 & 1.76 \\
\hline 9. Gender & -.10 & -.03 & .04 & .04 & -.08 & -.05 & -.05 & -.03 & 0.48 & 0.50 \\
\hline
\end{tabular}

Note: $N=272$. Performance rated by leaders; all other variables are follower rated. Values in parentheses indicate Cronbach alphas. $\mathrm{LMX}=$ leader-member exchange; $\mathrm{T} 1=$ Time $1 ; \mathrm{T} 2=$ Time 2.

${ }^{\mathrm{a}} 1=$ Female, $0=$ Male.

$* p<.05$.

$* * p<.01$.

combined. For example, the model with all items combined into a single factor $\left(\chi^{2}=\right.$ $3,490.53, d f=464, p<.001 ; \mathrm{CFI}=.34 ; \mathrm{TLI}=.29 ; \mathrm{RMSEA}=.16)$ produced a poorer model fit $\left(\Delta \chi^{2}=2,579.41, \Delta d f=10, p<.001\right)$.

\section{Analytical Approach}

As in Study 1, the participants consisted of individuals nested within teams, and the ICC(1) (Bliese, 2000) for task performance was found to be a modestly high value of .31 (Bliese, 1998), indicating that a portion of the variance could be accounted for by team membership. Thus, because the data structure violated the assumption of independence, we used the multilevel mediation approach described by Bauer et al. (2006). Our analysis was conducted in two steps. First, we tested a mediation model whereby we explored whether the relationship between LMX ambivalence $(\mathrm{X})$ and task performance $(\mathrm{Y})$ was mediated by negative affect $(\mathrm{M})$. Second, we tested a moderated mediation model (Hayes \& Preacher, 2010) in which the relationship between LMX ambivalence and negative affect was moderated by CWS (Z; i.e., the first stage of the indirect effect was moderated). For the second moderated mediation model, in the equation predicting $\mathrm{M}$, we included the interaction term between LMX ambivalence and CWS $(\mathrm{X} \times \mathrm{Z})$ in order to test Hypothesis 5. Before creating the interaction term, both the independent and moderator variables were grand-mean centered. Both equations also included a separate intercept that was allowed to vary within each equation across individuals and teams as well as between each equation.

\section{Hypothesis Testing}

We conducted the analytic method outlined above using mixed method analysis in SPSS (Version 23). The results provided support for Hypothesis 3 (see Table 4), showing that LMX 
Table 4

Multilevel Analysis: Effect of Leader-Member Exchange Ambivalence (X) and Coworker Support (Z) on Negative Affect (M) and Effect of Negative Affect on Task Performance (Y)

\begin{tabular}{|c|c|c|c|c|c|c|}
\hline & \multicolumn{3}{|c|}{ Negative Affect $(M) X \rightarrow M$} & \multicolumn{3}{|c|}{ Task Performance (Y) M $\rightarrow \mathrm{Y}$} \\
\hline & Coefficient & $S E$ & $t$ & Coefficient & $S E$ & $t$ \\
\hline \multicolumn{7}{|l|}{ Mediation Model } \\
\hline Intercept & 1.69 & 0.48 & $3.53 * *$ & 1.50 & 0.59 & $2.53 *$ \\
\hline \multicolumn{7}{|l|}{ Controls } \\
\hline Age & -.00 & .02 & -0.20 & -.01 & .02 & -0.31 \\
\hline Gender $^{\mathrm{a}}$ & .12 & .08 & 1.51 & .03 & .07 & 0.45 \\
\hline LMX & -.05 & .08 & -0.57 & -.16 & .09 & -1.89 \\
\hline $\mathrm{LMX} \times \mathrm{LMX}$ & .07 & .07 & 0.93 & -.03 & .07 & -0.48 \\
\hline Positive Affect & & & & .18 & .06 & $2.88 * *$ \\
\hline Task Performance (Time 1) & & & & .54 & .05 & $10.45 * *$ \\
\hline \multicolumn{7}{|l|}{$\mathrm{X}$} \\
\hline LMX Ambivalence & .24 & .06 & $3.83 * *$ & -.06 & .06 & -0.98 \\
\hline \multicolumn{7}{|l|}{ M } \\
\hline Negative Affect & & & & -.15 & .06 & $-2.46^{*}$ \\
\hline \multicolumn{7}{|l|}{ Moderated Mediation Model } \\
\hline Intercept & 1.76 & 0.47 & $3.70 * *$ & 1.46 & 0.60 & $2.43 *$ \\
\hline \multicolumn{7}{|l|}{ Controls } \\
\hline Age & -.01 & .02 & -0.38 & -.00 & .02 & -0.22 \\
\hline Gender ${ }^{\mathrm{a}}$ & .11 & .08 & 1.49 & .02 & .07 & 0.32 \\
\hline LMX & -.08 & .08 & -0.98 & -.14 & .09 & -1.66 \\
\hline LMX $\times$ LMX & .01 & .07 & 0.19 & -.01 & .07 & -0.20 \\
\hline Positive Affect & & & & .17 & .06 & $2.79 * *$ \\
\hline Task Performance (Time 1) & & & & .54 & .05 & $10.39 * *$ \\
\hline \multicolumn{7}{|l|}{$\mathrm{X}$} \\
\hline LMX Ambivalence & .18 & .06 & $2.84 * *$ & -.05 & .06 & -0.79 \\
\hline \multicolumn{7}{|l|}{$\mathrm{Z}$} \\
\hline CWS & -.14 & .06 & $-2.29 * *$ & .05 & .06 & 0.82 \\
\hline \multicolumn{7}{|l|}{$X \times Z$} \\
\hline LMX Ambivalence $\times$ CWS & -.20 & .07 & $-2.72 * *$ & & & \\
\hline \multicolumn{7}{|l|}{ M } \\
\hline Negative Affect & & & & -.14 & .06 & $-2.26^{*}$ \\
\hline
\end{tabular}

Note: Individual $N=272$; Team $N=115$. Estimation method = restricted maximum likelihood. LMX $=$ leadermember exchange; CWS = coworker support.

${ }^{\mathrm{a}} 1=$ Female, $0=$ Male.

$* p<.05$.

$* * p<.01$.

ambivalence had a significant relationship with negative affect $(y=.24, t(265)=3.83, p<.001)$. Hypothesis 4 predicted that negative affect would mediate the relationship between LMX ambivalence and task performance. We found evidence for this mediation effect. Specifically, we found that negative affect was significant and negatively related to task performance $(y=-.15, t(244)=$ $-2.47, p=.014)$. In order to test the significance of the mediated pathway, we calculated $95 \%$ 
Figure 3

Moderating Effect of Coworker Support on the Relationship Between Leader-Member Exchange Ambivalence and Negative Affect for High $(+1 S D)$ and Low (-1 SD) Coworker Support for Study 2

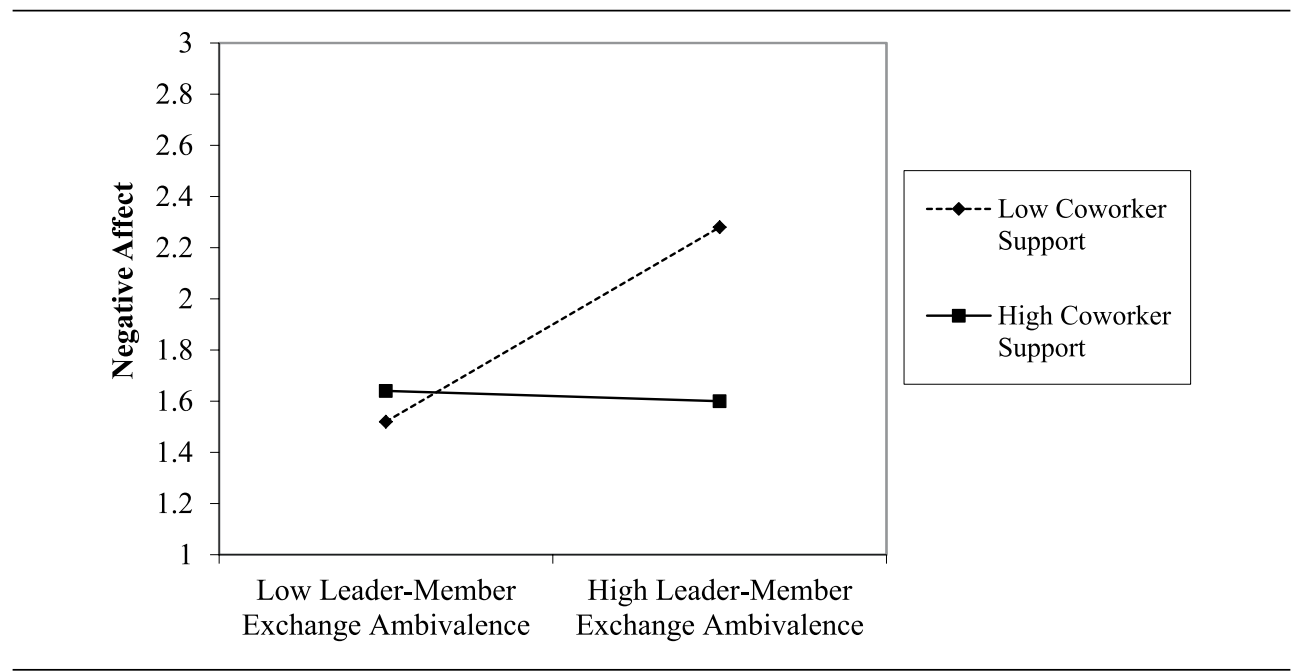

Monte Carlo confidence intervals by means of running simulations with 20,000 repetitions (Bauer et al., 2006). A significant mediation was found as the $95 \%$ confidence intervals did not include 0 (lower limit $(L L)=-.07$, upper limit $(U L)=-.01)$, with an indirect effect of -.04 .

Hypothesis 5 predicted moderated mediation. Specifically, we suggested that CWS would moderate the relationship between LMX ambivalence and negative affect. The interactive effect of LMX ambivalence and CWS on negative affect was significant $(\gamma=-.20, t(260)=-2.72, p=$ .007). To facilitate interpretation, we plotted and probed the simple slopes for low levels $(-1 S D)$ and high levels $(+1 S D)$ of CWS (Bauer et al., 2006). As predicted, Figure 3 shows a stronger positive slope at lower levels of CWS $(\gamma=.33, t(260)=3.82, p<.001)$ than at higher levels of CWS $(\gamma=.03, t(259)=0.40, p=.691)$. Thus, we found support for a moderation effect of CWS - the negative effects of LMX ambivalence were not present when CWS was high.

We further found that negative affect was significantly and negatively related to task performance $(y=-.14, t(240)=-2.26, p=.025)$. In order to test the significance of the mediated pathway, we again calculated $95 \%$ Monte Carlo confidence intervals by means of running simulations with 20,000 repetitions (Bauer et al., 2006). A significant mediation was found at low levels of the moderator as the $95 \%$ confidence intervals did not include $0(L L=-.10$, $U L=-.01)$, with an indirect effect of -.05 . At high levels of CWS, evidence of mediation was not found $(L L=-.03, U L=.02)$, with an indirect effect of .00 . This supported Hypothesis 5 in that the stronger effects of LMX ambivalence on task performance at lower versus higher levels of CWS were brought about by higher levels of negative affect.

\section{Discussion}

The results provided support for our hypotheses by showing significant associations between LMX ambivalence and negative affect as well as between negative affect and 
performance. We also found support for the role of CWS in moderating this mediated relationship between LMX ambivalence and performance. High levels of support nullified the relationship between LMX ambivalence and negative affect, supporting our cross-domain buffering hypothesis (Duffy et al., 2002), which posited that social support from coworkers would ameliorate the negative consequences of an ambivalent leaderfollower relationship. As in Study 1, these effects were shown when controlling for LMX quality and the quadratic term of LMX quality, suggesting that LMX ambivalence has effects beyond those of LMX quality and the curvilinear effects of LMX. These results suggest that negative affect mediates the LMX ambivalence-performance relationship.

\section{General Discussion}

We sought to address two principal aims: first, we tested whether our newly developed construct, LMX ambivalence, had a deleterious impact on task performance (while controlling for LMX quality). Second, we investigated the role of contextual factors, in the form of two external sources of social support (POS and CWS), in buffering the LMX ambivalencetask performance relationship. The pattern of results was consistent across both studies (as well as our additional validation studies; see online supplemental material) in supporting the validity of LMX ambivalence, its negative impact on task performance, and the ambivalence-buffering role of social support. In addition, using a time-ordered design, in Study 2, we found initial evidence for negative affect as an underlying mechanism that helps to explain the LMX ambivalence-performance relationship. These results have important implications for theory and research on both LMX and ambivalence, to which we now turn.

\section{Theoretical Implications}

The primary contribution of our research to LMX theory is the extension of the LMX concept to include LMX ambivalence (captured as the coexistence of positive and negative cognitions regarding the LMX relationship). Since its inception, LMX theory has construed LMX quality as exclusively univalent (i.e., low vs. high quality; see Lee et al., 2015). Yet our research shows that LMX can also be conceptualized and measured as bivalent (i.e., ambivalent: both low and high quality). LMX ambivalence is a meaningful construct that across five studies (i.e., two primary studies and three initial validation studies) has demonstrated good evidence of discriminant, predictive, and incremental validity beyond that of LMX quality (and other related constructs). Our findings suggest that a subjective assessment of one's LMX ambivalence is a distinct construct that is not captured in current conceptualizations and measures of LMX quality (e.g., LMX7).

At the heart of the LMX ambivalence concept is the notion of inconsistency. Relatedly, in their review of the literature pertaining to the fourth and most recent stage of LMX theory development, Graen and Uhl-Bien (1995) noted the existence of significant variation in LMX quality between leader-follower dyads in the same work group because leaders vary in their treatment of different followers (i.e., LMX differentiation). The critical point, however, is that the LMX ambivalence concept extends this assumption of inconsistency to within leader-follower dyads because our results imply that leaders may be inconsistent in their treatment of the same followers. Thus, LMX ambivalence constitutes a different view of inconsistency that complements and advances our understanding of the nature of LMX relationships. 
It is important to highlight the performance implications of LMX ambivalence. The findings across both studies revealed a negative relationship between LMX ambivalence and task performance, while controlling for the (linear and quadratic) effects of LMX quality. Therefore, on the basis of the evidence of the current investigation, LMX ambivalence makes a substantive contribution to the explanatory power of LMX theory and its implications for follower performance.

As well as demonstrating a link between LMX ambivalence and task performance, our findings provide initial support for negative affect as a mediator that can explain this link. This represents an important theoretical contribution for several reasons. First, while negative affect is central to explaining the negative effects of ambivalence, few studies have empirically tested it as an outcome of ambivalence (e.g., Newby-Clark et al., 2002; Nordgren et al., 2006), and little is known about the emotional consequences of cognitive ambivalence and whether negative emotional responses can explain the detrimental effects on employee behavior. We argued and showed that the effects of LMX ambivalence can be explained by the notion of ambivalence-induced negative affect (van Harreveld et al., 2015), which suggests that holding contrasting cognitions about the same object is indeed aversive because it violates fundamental consistency motives (Festinger, 1957).

A second contribution of exploring negative affect as a mediator is that it represents an important and previously untested mediator in the context of LMX theory. As an affective process, negative affect differs from the types of constructs proposed by the social exchange theory explanation of LMX, such as felt obligation (e.g., Lemmon \& Wayne, 2015). In Study 2 , we found initial support for negative affect as an explanatory variable that can help explain the deleterious effects of LMX ambivalence. This is in line with recent theorizing that suggests that emotions are highly relevant at the various stages in the development of the LMX relationship (Cropanzano, Dasborough, \& Weiss, 2017). Thus, while our study did not explore the affective consequences of overall LMX quality, the consideration of negative affect in the context of LMX ambivalence provides support for the utility of examining the role of affective processes in LMX relationships more generally (Cropanzano et al., 2017). Given the fact that we assessed the mediating role of negative affect in only one of our studies, further tests of this mediated pathway are needed to add confidence to this finding. It should also be noted that the indirect effect found in Study 2 was relatively small (-.04), suggesting that other factors may explain additional variance between LMX ambivalence and task performance. Interestingly, a recent meta-analysis (Martin et al., 2016) posited a number of theoretical approaches that could explain the link between LMX quality and employee behavior. It would be interesting for future research to assess additional mediators that represent other theoretical approaches in relation to LMX ambivalence, such as social exchange and self-determination theories. For instance, by adopting a social exchange framework (Cropanzano \& Mitchell, 2005), followers' trust in the leader may provide an additional explanation for the LMX ambivalence-performance relationship. Indeed, in the Martin et al. (2016) LMX quality-performance meta-analysis, trust in the leader accounted for the most variance in the mediation models for both task performance and citizenship behavior. Specifically, perceptions of ambivalence within the LMX relationship might signal to the follower that the leader is less trustworthy. For instance, Levin (1999) suggested that leaders can build trust by doing what they say they are going to do (credibility) and behaving in a predictable manner (consistency). The presence of ambivalence implies that leaders may not be predictable or credible in their followers' eyes, and this inconsistency may lead to a lack 
of trust. Consistent behavior, in particular, displays commitment and predictability, which are key attributes for promoting trust (Burke, Sims, Lazzara, \& Salas, 2007).

By extending the foci of ambivalence to a different target, namely, the leader-follower relationship, our research also advances the current understanding of workplace ambivalence in a number of important ways. First, and most importantly, while previous ambivalence research has found negative effects of, for example, ambivalent organizational identification (e.g., Schuh et al., 2016), such studies have largely failed to explore moderator variables that either attenuate or accentuate the effects of ambivalence. Indeed, Rothman and colleagues highlighted, in relation to the effects of ambivalence, that "empirical research on organizational moderators and boundary conditions remains relatively scant, and much existing management work remains theoretical" (2017: 62). Across two studies, we demonstrated that the presence of high levels of social support negates the normally negative effect of LMX ambivalence on task performance. This finding might extrapolate to other foci: for example, reducing the negative effects of ambivalent organizational identification. In the current research, we showed that perceptions of both coworker and organizational support mitigate the negative effects of LMX ambivalence. Other forms of support could also be investigated as further boundary conditions. For instance, rather than focusing on sources of support within the organization, it would be interesting to assess whether support from outside the organization can also ameliorate the negative link between LMX ambivalence and performance. For example, social support from friends and family outside of the workplace has been found to reduce the impact of work stress on employee outcomes (Huynh, Xanthopoulou, \& Winefield, 2013).

A second way our research furthers understanding of workplace ambivalence is by highlighting when ambivalence leads to detrimental rather than beneficial outcomes. While ambivalence has traditionally been viewed as something to be avoided, recently research has begun to explore, and find evidence for, the beneficial effects of ambivalence (e.g., Zou \& Ingram, 2013). As discussed by Methot and colleagues (2017), research exploring the consequences of ambivalent relationships has reported mixed results. On the one hand, ambivalent relationships have, for example, been associated with detrimental health outcomes (Uchino et al., 2014). On the other hand, some research suggests that ambivalent relationships may also have functional workplace outcomes (e.g., Rothman \& Melwani, 2017). In line with the propositions of Rothman and colleagues' (2017) recent review, we demonstrated that deleterious effects of ambivalence are driven by the experience of negative affect. Our findings are also in line with the proposition that ambivalence towards an important target (i.e., the leaderfollower relationship) would elicit such negative affective responses (Pratt \& Pradies, 2011). Future research should further our understanding of when and how different forms of ambivalence lead to salutary or detrimental effects. For example, Guarana and Hernandez (2016) suggest that individuals who can correctly recognize the causes of their ambivalence (e.g., a relationship partner) are better able to process relevant situational cues that enable effective decision-making. It therefore seems reasonable to assume that outcomes that require high levels of information processing, such as decision-making, creativity, and learning, might under the right conditions benefit from ambivalence.

A third way our research advances understanding of workplace ambivalence is by its focus on task performance as an outcome. Ambivalence researchers have highlighted that a critical step for future research is the investigation of the effects of ambivalence on employee behavior (Ashforth et al., 2014; Methot et al., 2017). Our research contributes to this 
literature by demonstrating that LMX ambivalence is negatively associated with employee task performance, a finding that was replicated in both studies. Being one of the first studies of workplace ambivalence to explore task performance as an outcome, our findings have pertinent practical implications and add support to previous research showing the negative implications of ambivalence in the form of ambivalent identification (e.g., Pratt \& Doucet, 2000). Furthermore, we found evidence of negative effects of LMX ambivalence while controlling for the overall quality of LMX. This is important as we demonstrated the incremental predictive validity of ambivalence. Previous research has not always found support for such validity. For instance, Ashforth, Joshi, Anand, and O'Leary-Kelly (2013) showed that ambivalent identification had incremental predictive validity beyond that of identification and disidentification in terms of predicting employee burnout, stress, and turnover intentions but not deviant behavior or organizational citizenship behavior (OCB). A more recent study found only a small main effect of ambivalent identification on OCB directed at the organization and no significant effect on OCB directed at peers over and above that of identification (Schuh et al., 2016). We found that LMX ambivalence has incremental predictive validity above that of LMX quality. This represents an important contribution to the ambivalence literature by demonstrating the key role it may play in influencing employees' behavior and the value of considering it over unidimensional measures. It also highlights the utility of moving the foci of ambivalence research from organizational identification to the context of the leader-follower relationship. Our findings suggest that ambivalence in this context is a significant predictor of employee behavior. Such findings add further veracity to the call for research to further account for the effects of ambivalence in the wider context of management (Ashforth et al., 2014) and within workplace relationships (Methot et al., 2017). In the current studies, we did not measure organizational identification or ambivalent identification; thus, we could not determine whether LMX ambivalence has incremental predictive validity beyond that of these constructs. Future research could aim to determine the relative predictive validity of these different constructs or, indeed, whether reduced or ambivalent identification mediates the effects of high LMX ambivalence. To that end, it would also be of interest to explore additional outcome variables beyond task performance, such as counterproductive performance.

\section{Implications for Practice}

Given the detrimental effects of LMX ambivalence, it is important that leaders and HR professionals understand how to mitigate the effects of relational ambivalence. An important finding of the current research was the mitigating role that social support plays in ameliorating the negative effects of ambivalence. The results show that in the context of high levels of POS (Study 1) and CWS (Study 2), LMX ambivalence does not adversely influence employee performance. Leaders and HR professionals need to ensure the provision of organizational support and foster opportunities for CWS in order to buffer the effects of LMX ambivalence. For example, HR practices can be used to encourage investment in employees and show recognition of employee contributions and signal that the organization is supportive and is seeking to establish or continue a positive social exchange relationship with employees (Allen, Shore, \& Griffeth, 2003). Similarly, organizations should also consider the buffering role played by CWS in mitigating the deleterious effects of LMX ambivalence. Thus, organizations should consider improving CWS schemes in the workplace, such as developing 
informal mentoring schemes, to enable individuals to increase their network resources. Organizations could also develop a culture where interaction between employees at different levels and from different departments is encouraged. This may be done by organizing networking days where employees from various departments are able to interact and by encouraging employees to socialize outside of work.

In addition to the mitigating role played by both POS and CWS, an additional way in which organizations might seek to disrupt the link between LMX ambivalence and negative affect is through the management of employees' perceptions. For instance, knowing that LMX ambivalence is a common experience may be comforting when employees experience it. The appreciation that LMX ambivalence is commonplace in organizations could help mitigate the connection between LMX ambivalence and negative affect by managing employees' expectations. Leaders should also be encouraged to consider their own behavior in order to be more consistent in their dealings with employees. While it may not always be possible to have solely positive interactions with followers, behavioral consistency is one way leaders can reduce the potential for ambivalence. Research has demonstrated that leaders who are perceived as inconsistent are evaluated as less procedurally fair and engender feelings of uncertainty about future interactions (De Cremer, 2003). Lian et al. (2012) have also demonstrated the negative effects of mixed relationships (characterized by both high LMX quality and abusive supervision). These findings could inform leader training and development by emphasizing the importance of behavioral consistency.

\section{Study Strengths and Potential Limitations}

The current research has some notable strengths. The inclusion of multiple studies (including those in the online supplemental material) provides strong support for some of our central arguments. For example, across five studies, we were able to demonstrate that LMX ambivalence is distinct from overall LMX quality. The effects of LMX ambivalence on task performance were also found while controlling for overall LMX quality (both linear and quadratic terms), highlighting the incremental predictive validity of our measure. The use of temporally ordered methods in Study 2 provided a stronger test of the directional links between LMX ambivalence and task performance, especially given that we also included baseline (i.e., previously rated) performance, thereby enabling the examination of the unique effects of LMX ambivalence on performance levels, controlling for previous performance. Finally, in both studies, we collected data from leaders and followers, an aspect of the research design that reduces the potential for common method and source bias explanations for the reported results.

Despite these strengths, we should note the potential limitations associated with the current research. First, although we were able to provide a temporally ordered test of the key relationships (in Study 2), only experiments are able, in a strict sense, to demonstrate the causality of any given relationship. Furthermore, Study 2 also relied on dyadic data from leaders and members working within student project teams. While the attributes of these teams are in many ways comparable to those of project teams in an organizational context (e.g., high level of member responsibility, required task interdependence, and cooperation), more research is needed to enable generalization of the findings to different forms of leadership in organizations. However, leadership researchers testing their hypotheses in both student and field samples have found that results replicate over the samples (e.g., van Knippenberg \& van Knippenberg, 2005). In fact, our research showed that the effects in the 
student sample were comparable to those of the organizational sample: the main effect and the moderating effects of social support were replicated across samples. Furthermore, previous longitudinal investigations of LMX development have utilized similar student project teams (Nahrgang et al., 2009), and empirical evidence from samples in academic contexts and work teams has been shown to be comparable (see van Vianen \& De Dreu, 2001).

A second potential limitation is the fact that we measured our mediation variable (negative affect) in Study 2 only. While the findings of Study 2 provide some support for our theoretical framework, further tests of this mediated pathway are needed to add confidence to this finding. Even so, our findings are in line with previous research on the effects of ambivalence on emotional responses in relationships (e.g., Uchino, HoltLunstad, Smith, \& Bloor, 2004), which suggests that negative affect might indeed mediate the effects. As mentioned above, future research should try to replicate our findings and could explore additional mediators that might also explain the link between LMX ambivalence and task performance.

A final potential limitation is the fact that in both studies, we did not control for ambivalent leader identification. As shown in the online supplemental material, this measure of ambivalence towards the leader (as opposed to the relationship) was highly correlated with LMX ambivalence. Nevertheless, in line with previous research (e.g., Gu et al., 2015), we demonstrated that LMX ambivalence has incremental validity over ambivalent leader identification (see online supplemental material). However, future research should continue to assess the incremental validity of LMX ambivalence over ambivalence in relation to other sources, such as the leader (i.e., ambivalent leader identification), the organization (i.e., ambivalent organizational identification), and coworkers (i.e., coworker relational ambivalence).

Other factors, aside from social support, are also likely to play a moderating role in determining when LMX ambivalence will be more or less impactful. For example, individuals who have tendencies towards negativity and emotionality may be particularly sensitive to ambivalent relationship experiences (Rusbult \& Van Lange, 2003). Similarly, rumination is an individual difference construct that is likely to exacerbate the effects of ambivalence, as constantly mulling over ambivalent thoughts is likely to chronically prime the negative component of an individual's ambivalence (Kachadourian, Fincham, \& Davila, 2005). Future research might also investigate situations where ambivalent LMX relationships might lead to positive outcomes. Recently, scholars have provided integrative frameworks detailing distinct ways in which individuals might deal with ambivalence (Ashforth et al., 2014; Rothman et al., 2017). The authors suggest that different responses to ambivalence might lead to positive and negative outcomes. For instance, Ashforth and colleagues (2014) suggest that a holistic response to ambivalence involves the complete, simultaneous, and conscious acceptance of both opposing orientations. Therefore, according to the authors, holism is a proactive response that may allow individuals to develop a more comprehensive understanding of the duality at the heart of ambivalence. Furthermore, because the authors argue that a holistic response requires the voluntary acceptance of ambivalence, it is transformed into something over which the individual has at least some control (Ashforth et al., 2014). This control and acceptance of ambivalence could lead to some positive effects of ambivalence. In the context of the LMX relationship, therefore, this framework suggests that if employees can learn to accept their ambivalent cognitions, it could create the opportunity for the development of positive relationship outcomes. 
It should also be noted that the current studies focused on the effects of subjective cognitive ambivalence and the resulting ambivalence-induced negative affect. As mentioned previously, ambivalence research has also examined the affective or emotional dimensions of attitudinal ambivalence (e.g., Thompson et al., 1995). The present research focused on conflicting evaluations within the cognitive dimension of individuals' attitude towards their LMX relationship. Future research, however, could also investigate affective ambivalence or affective cognitive inconsistency and how these types of ambivalence influence the LMX relationship. We noted that the LMX7 scale (our adapted measure of LMX ambivalence) is a cognitive measure of the leader-follower relationship (Lee et al., 2015), but another measure, namely, LMX-MDM (Liden \& Maslyn, 1998), has both affective and cognitive dimensions (Lee et al., 2015) and, thus, could be adapted in order to assess other types of ambivalence.

\section{Conclusion}

In this paper, we have provided an empirical examination of LMX ambivalence, and the results show its importance for explaining task performance beyond that of LMX quality. This initial test of LMX ambivalence provided support for the propositions of ambivalence research by highlighting the role of negative emotions in undermining task performance. We also found support for the cross-domain buffering effect of social support from both coworkers and the organization, thus providing practical clues as to how organizations can ameliorate the detrimental effects of LMX ambivalence. Thus, workplace relationships are important in that they can elicit and alleviate ambivalence. We argue that it is time to move beyond focusing on just high- versus low-quality LMX relationships and begin to also consider those that are both high and low quality.

\section{References}

Allen, D. G., Shore, L. M., \& Griffeth, R. W. 2003. The role of perceived organizational support and supportive human resource practices in the turnover process. Journal of Management, 29: 99-118.

Ashforth, B. E., Joshi, M., Anand, V., \& O’Leary-Kelly, A. M. 2013. Extending the expanded model of organizational identification to occupations. Journal of Applied Social Psychology, 43: 2426-2448.

Ashforth, B. E., Rogers, K. M., Pratt, M. G., \& Pradies, C. 2014. Ambivalence in organizations: A multilevel approach. Organization Science, 25: 1453-1478.

Baek, Y. M. 2010. An integrative model of ambivalence. The Social Science Journal, 47: 609-629.

Balkundi, P., \& Harrison, D. A. 2006. Ties, leaders, and time in teams: Strong inference about network structure's effects on team viability and performance. Academy of Management Journal, 49: 49-68.

Bassili, J. N. 1996. Meta-judgmental versus operative indexes of psychological attributes: The case of measures of attitude strength. Journal of Personality and Social Psychology, 71: 637-653.

Bauer, D. J., Preacher, K. J., \& Gil, K. M. 2006. Conceptualizing and testing random indirect effects and moderated mediation in multilevel models: New procedures and recommendations. Psychological Methods, 11: 142-163.

Baumeister, R. F., Bratslavsky, E., Finkenauer, C., \& Vohs, K. D. 2001. Bad is stronger than good. Review of General Psychology, 5: 323-370.

Beal, D. J., Weiss, H. M., Barros, E., \& MacDermid, S. M. 2005. An episodic process model of affective influences on performance. Journal of Applied Psychology, 90: 1054-1068.

Blau, P. M. 1964. Exchange and power in social life. New Brunswick, NJ: Transaction.

Bliese, P. D. 1998. Group size, ICC values, and group-level correlations: A simulation. Organizational Research Methods, 1: 355-373.

Bliese, P. D. 2000. Within-group agreement, non-independence, and reliability: Implications for data aggregation and analysis. In K. J. Klein \& S. W. J. Kozlowski (Eds.), Multilevel theory, research, and methods in organizations: 349-381. San Francisco: Jossey-Bass. 
Burke, C. S., Sims, D. E., Lazzara, E. H., \& Salas, E. 2007. Trust in leadership: A multi-level review and integration. The Leadership Quarterly, 18: 606-632.

Burris, E. R., Detert, J. R., \& Chiaburu, D. S. 2008. Quitting before leaving: The mediating effects of psychological attachment and detachment on voice. Journal of Applied Psychology, 93: 912-922.

Bushman, B. B., \& Holt-Lunstad, J. 2009. Understanding social relationship maintenance among friends: Why we don't end those frustrating friendships. Journal of Social and Clinical Psychology, 28: 749-778.

Campo, R. A., Uchino, B. N., Holt-Lunstad, J., Vaughn, A., Reblin, M., \& Smith, T. W. 2009. The assessment of positivity and negativity in social networks: The reliability and validity of the social relationships index. Journal of Community Psychology, 37: 471-486.

Chuang, A., Judge, T. A., \& Liaw, Y. J. 2012. Transformational leadership and customer service: A moderated mediation model of negative affectivity and emotion regulation. European Journal of Work and Organizational Psychology, 21: 28-56.

Cohen, J., Cohen, P., West, S. G., \& Aiken, L. S. 2003. Applied multiple regression/correlation analysis for the behavioral sciences (3rd ed.). Hoboken, NJ: Taylor \& Francis.

Costarelli, S., \& Colloca, P. 2004. The effects of attitudinal ambivalence on pro-environmental behavioural intentions. Journal of Environmental Psychology, 24: 279-288.

Cropanzano, R., Dasborough, M. T., \& Weiss, H. M. 2017. Affective events and the development of leader-member exchange. Academy of Management Review, 42: 233-258.

Cropanzano, R., \& Mitchell, M. S. 2005. Social exchange theory: An interdisciplinary review. Journal of Management, 31: 874-900.

Dansereau, F., Graen, G., \& Haga, W. J. 1975. A vertical dyad linkage approach to leadership within formal organizations: A longitudinal investigation of the role making process. Organizational Behavior and Human Performance, 13: 46-78.

De Cremer, D. 2003. Why inconsistent leadership is regarded as procedurally unfair: The importance of social selfesteem concerns. European Journal of Social Psychology, 33: 535-550.

De Dreu, C., West, M., Fischer, A., \& MacCurtain, S. 2001. Origins and consequences of emotions in organizational teams. In R. L. Payne \& C. L. Cooper (Eds.), Emotions at work: Theory, research and applications for management: 199-219. Chichester, England: John Wiley \& Sons.

Demerouti, E., Bakker, A. B., \& Bulters, A. J. 2004. The loss spiral of work pressure, work-home interference and exhaustion: Reciprocal relations in a three-wave study. Journal of Vocational Behavior, 64: 131-149.

Duffy, M. K., Ganster, D. C., \& Pagon, M. 2002. Social undermining in the workplace. Academy of Management Journal, 45: 331-351.

Dulebohn, J. H., Bommer, W. H., Liden, R. C., Brouer, R. L., \& Ferris, G. R. 2012. A meta-analysis of antecedents and consequences of leader-member exchange integrating the past with an eye toward the future. Journal of Management, 38: 1715-1759.

Eisenberger, R., Armeli, S., Rexwinkel, B., Lynch, P. D., \& Rhoades, L. 2001. Reciprocation of perceived organizational support. Journal of Applied Psychology, 86: 42-51.

Feldner, M., Leen-Feldner, E., Zvolensky, M., \& Lejuez, C. 2006. Examining the association between rumination, negative affectivity, and negative affect induced by a paced auditory serial addition task. Journal of Behavior Therapy and Experimental Psychiatry, 37: 171-187.

Festinger, L. 1957. A theory of cognitive dissonance. Stanford, CA: Stanford University Press.

Fincham, F. D., \& Linfield, K. J. 1997. A new look at marital quality: Can spouses feel positive and negative about their marriage? Journal of Family Psychology, 11: 489-502.

Fingerman, K. 2001. A distant closeness: Intimacy between parents and their children in later life. Generations, 25: 26-33.

Fingerman, K. L., Pitzer, L., Lefkowitz, E. S., Birditt, K. S., \& Mroczek, D. 2008. Ambivalent relationship qualities between adults and their parents: Implications for the well-being of both parties. The Journals of Gerontology Series B: Psychological Sciences and Social Sciences, 63: 362-371.

Graen, G. B., \& Uhl-Bien, M. 1995. Relationship-based approach to leadership: Development of leader-member exchange (LMX) theory of leadership over 25 years: Applying a multi-level multi-domain perspective. The Leadership Quarterly, 6: 219-247.

Green, C., Jegadeesh, N., \& Tang, Y. 2009. Gender and job performance: Evidence from Wall Street. Financial Analysts Journal, 65: 65-78.

Gu, Q., Tang, T. L. P., \& Jiang, W. 2015. Does moral leadership enhance employee creativity? Employee identification with leader and leader-member exchange (LMX) in the Chinese context. Journal of Business Ethics, 126: 513-529. 
Guarana, C. L., \& Hernandez, M. 2016. Identified ambivalence: When cognitive conflicts can help individuals overcome cognitive traps. Journal of Applied Psychology, 101: 1013-1029.

Halbesleben, J. R., Neveu, J. P., Paustian-Underdahl, S. C., \& Westman, M. 2014. Getting to the "COR": Understanding the role of resources in conservation of resources theory. Journal of Management, 40: 13341364.

Hayes, A. F., \& Preacher, K. J. 2010. Quantifying and testing indirect effects in simple mediation models when the constituent paths are nonlinear. Multivariate Behavioral Research, 45: 627-660.

Haynes, C. E., Wall, T. D., Bolden, R. I., Stride, C., \& Rick, J. E. 1999. Measures of perceived work characteristics for health services research: Test of a measurement model and normative data. British Journal of Health Psychology, 4: 257-275.

Henderson, D. J., Liden, R. C., Glibkowski, B. C., \& Chaudhry, A. 2009. LMX differentiation: A multilevel review and examination of its antecedents and outcomes. The Leadership Quarterly, 20: 517-534.

Hobman, E. V., Restubog, S. L. D., Bordia, P., \& Tang, R. L. 2009. Abusive supervision in advising relationships: Investigating the role of social support. Applied Psychology, 58: 233-256.

Holt-Lunstad, J., Uchino, B. N., Smith, T. W., \& Hicks, A. 2007. On the importance of relationship quality: The impact of ambivalence in friendships on cardiovascular functioning. Annals of Behavioral Medicine, 33: 278-290.

Hoobler, J. M., \& Hu, J. 2013. A model of injustice, abusive supervision, and negative affect. The Leadership Quarterly, 24: 256-269.

Huckfeldt, R., Mendez, J. M., \& Osborn, T. 2004. Disagreement, ambivalence, and engagement: The political consequences of heterogeneous networks. Political Psychology, 25: 65-95.

Huynh, J. Y., Xanthopoulou, D., \& Winefield, A. H. 2013. Social support moderates the impact of demands on burnout and organizational connectedness: A two-wave study of volunteer firefighters. Journal of Occupational Health Psychology, 18: 9-15.

Ingram, P., \& Roberts, P. W. 2000. Friendship among competitors in the Sydney hotel industry. American Journal of Sociology, 106: 387-423.

Kachadourian, L. K., Fincham, F., \& Davila, J. 2005. Attitudinal ambivalence, rumination, and forgiveness of partner transgressions in marriage. Personality and Social Psychology Bulletin, 31: 334-342.

Klopfer, F. J., \& Madden, T. M. 1980. The middlemost choice on attitude items: Ambivalence, neutrality, or uncertainty? Personality and Social Psychology Bulletin, 61: 97-101.

Koy, A., \& Yeo, G. 2008. BIS sensitivity, negative affect and performance: Dynamic and multilevel relationships. Human Performance, 21: 198-225.

Lee, A., Martin, R., Thomas, G., Guillaume, Y., \& Maio, G. R. 2015. Conceptualizing leadership perceptions as attitudes: Using attitude theory to further understand the leadership process. The Leadership Quarterly, 26: 910-934.

Lemmon, G., \& Wayne, S. J. 2015. Underlying motives of organizational citizenship behavior comparing egoistic and altruistic motivations. Journal of Leadership \& Organizational Studies, 22: 129-148.

Levin, D. Z. 1999. Transferring knowledge within the organization in the R\&D arena. Unpublished doctoral dissertation, Northwestern University, Evanston, IL.

Lian, H., Ferris, L. D., \& Brown, D. J. 2012. Does taking the good with the bad make things worse? How abusive supervision and leader-member exchange interact to impact need satisfaction and organizational deviance. Organizational Behavior and Human Decision Processes, 117: 41-52.

Liden, R. C., \& Maslyn, J. M. 1998. Multidimensionality of leader-member exchange: An empirical assessment through scale development. Journal of Management, 24: 43-72.

Lin, X., \& Leung, K. 2010. Differing effects of coping strategies on mental health during prolonged unemployment: A longitudinal analysis. Human Relations, 63: 637-665.

Martin, R., Epitropaki, O., Thomas, G., \& Topakas, A. 2010. A critical review of leader-member relationship (LMX) research: Future prospects and directions. International Review of Industrial and Organizational Psychology, 25: 61-91.

Martin, R., Guillaume, Y., Thomas, G., Lee, A., \& Epitropaki, O. 2016. Leader-member exchange (LMX) and performance: A meta-analytic review. Personnel Psychology, 69: 67-121.

Mathieu, J. E., \& Rapp, T. L. 2009. Laying the foundation for successful team performance trajectories: The roles of team charters and performance strategies. Journal of Applied Psychology, 94: 90-103.

Methot, J. R., Melwani, S., \& Rothman, N. B. 2017. The space between us: A social-functional emotions view of ambivalent and indifferent workplace relationships. Journal of Management, 43: 1789-1819. 
Mikulincer, M., Shaver, P. R., Bar-On, N., \& Ein-Dor, T. 2010. The pushes and pulls of close relationships: Attachment insecurities and relational ambivalence. Journal of Personality and Social Psychology, 98: 450-468.

Mor, N., \& Winquist, J. 2002. Self-focused attention and negative affect: A meta-analysis. Psychological Bulletin, 128: 638-662.

Mulligan, M. 2015. On ambivalence and hope in the restless search for community: How to work with the idea of community in the global age. Sociology, 49: 340-355.

Nahrgang, J. D., Morgeson, F. P., \& Ilies, R. 2009. The development of leader-member exchanges: Exploring how personality and performance influence leader and member relationships over time. Organizational Behavior and Human Decision Processes, 108: 256-266.

Newby-Clark, I. R., McGregor, I., \& Zanna, M. P. 2002. Thinking and caring about cognitive inconsistency: When and for whom does attitudinal ambivalence feel uncomfortable? Journal of Personality and Social Psychology, 82: 157-166.

Newman, A., Schwarz, G., Cooper, B., \& Sendjaya, S. 2017. How servant leadership influences organizational citizenship behavior: The roles of LMX, empowerment, and proactive personality. Journal of Business Ethics, 145: 49-62.

Ng, T. W., \& Feldman, D. C. 2010. The relationships of age with job attitudes: A meta-analysis. Personnel Psychology, 63: 677-718.

Nordgren, L. F., van Harreveld, F., \& van der Pligt, J. 2006. Ambivalence, discomfort, and motivated information processing. Journal of Experimental Social Psychology, 42: 252-258.

Oglensky, B. D. 2008. The ambivalent dynamics of loyalty in mentorship. Human Relations, 61: 419-448.

Palanski, M. E., \& Yammarino, F. J. 2011. Impact of behavioral integrity on follower job performance: A threestudy examination. The Leadership Quarterly, 22: 765-786.

Petty, R. E., \& Cacioppo, J. T. 1996. Addressing disturbing and disturbed consumer behavior: Is it necessary to change the way we conduct behavioral science? Journal of Marketing Research, 33: 1-8.

Pratt, M. G. 2000. The good, the bad, and the ambivalent: Managing identification among Amway distributors. Administrative Science Quarterly, 45: 456-493.

Pratt, M. G., \& Doucet, L. 2000. Ambivalent feelings in organizational relationships. In S. Fineman (Ed.), Emotion in organizations (2nd ed.): 204-226. London: Sage.

Pratt, M. G., \& Pradies, C. 2011. Just a good place to visit? Exploring positive responses to ambivalence. In K. Cameron \& G. Spreitzer (Eds.), Handbook of positive organizational scholarship: 924-937. New York: Oxford University Press.

Priester, J. M., \& Petty, R. E. 1996. The gradual threshold model of ambivalence: Relating the positive and negative bases of attitudes to subjective ambivalence. Journal of Personality and Social Psychology, 71: 431-449.

Rhoades, L., \& Eisenberger, R. 2002. Perceived organizational support: A review of the literature. Journal of Applied Psychology, 87: 698-714.

Rothman, N. B., \& Melwani, S. 2017. Feeling mixed, ambivalent, and in flux: The social functions of emotional complexity for leaders. Academy of Management Review, 42: 259-282.

Rothman, N., Pratt, M., Rees, L., \& Vogus, T. 2017. Understanding the dual nature of ambivalence: Why and when ambivalence leads to good and bad outcomes. The Academy of Management Annals, 11: 33-72.

Rotundo, M., \& Sackett, P. R. 2002. The relative importance of task, citizenship, and counterproductive performance to global ratings of job performance: A policy-capturing approach. Journal of Applied Psychology, 87: 66-80.

Rusbult, C. E., \& Van Lange, P. A. 2003. Interdependence, interaction, and relationships. Annual Review of Psychology, 54: 351-375.

Sarafino, E. P. 1997. Health psychology: Biopsychosocial interactions (3rd ed.). New York: Wiley.

Schuh, S. C., Van Quaquebeke, N., Göritz, A. S., Xin, K. R., De Cremer, D., \& van Dick, R. 2016. Mixed feelings, mixed blessing? How ambivalence in organizational identification relates to employees' regulatory focus and citizenship behaviors. Human Relations, 69: 2224-2249.

Sguera, F., Bagozzi, R. P., Huy, Q. N., Boss, R. W., \& Boss, D. S. 2016. Curtailing the harmful effects of workplace incivility: The role of structural demands and organization-provided resources. Journal of Vocational Behavior, 95: 115-127.

Sparrowe, R. T., \& Liden, R. C. 1997. Process and structure in leader-member exchange. Academy of Management Review, 22: 522-552.

Sparrowe, R. T., \& Liden, R. C. 2005. Two routes to influence: Integrating leader-member exchange and social network perspectives. Administrative Science Quarterly, 50: 505-535. 
Sturman, M. C. 2003. Searching for the inverted U-shaped relationship between time and performance: Metaanalyses of the experience/performance, tenure/performance, and age/performance relationships. Journal of Management, 29: 609-640.

Susskind, A. M., Kacmar, K. M., \& Borchgrevink, C. P. 2003. Customer service providers' attitudes relating to customer service and customer satisfaction in the customer-server exchange. Journal of Applied Psychology, 88: 179-187.

Thomas, G., Martin, R., Epitropaki, O., Guillaume, Y., \& Lee, A. 2013. Social cognition in leader-follower relationships: Applying insights from relationship science to understanding relationship-based approaches to leadership. Journal of Organizational Behavior, 34: S63-S81.

Thompson, M. M., \& Holmes, J. G. 1996. Ambivalence in close relationships: Conflicted cognitions as a catalyst for change. In R. M. Sorrentino \& E. T. Higgins (Eds.), Handbook of motivation and cognition, vol. 3: 497-530. New York: Guilford Press.

Thompson, M. M., Zanna, M. P., \& Griffin, D. W. 1995. Let's not be indifferent about attitudinal ambivalence. In R. E. Petty \& J. A. Krosnick (Eds.), Attitude strength: Antecedents and consequences: 361-386. Mahwah, NJ: Erlbaum.

Tsai, W. C., Chen, C. C., \& Liu, H. L. 2007. Test of a model linking employee positive moods and task performance. Journal of Applied Psychology, 92: 1570-1583.

Uchino, B. N., Holt-Lunstad, J., Smith, T. W., \& Bloor, L. 2004. Heterogeneity in social networks: A comparison of different models linking relationships to psychological outcomes. Journal of Social and Clinical Psychology, 23: $123-139$.

Uchino, B. N., Smith, T. W., \& Berg, C. A. 2014. Spousal relationship quality and cardiovascular risk: Dyadic perceptions of relationship ambivalence are associated with coronary-artery calcification. Psychological Science, 25: 1037-1042.

Uhl-Bien, M. 2006. Relational leadership theory: Exploring the social processes of leadership and organizing. The Leadership Quarterly, 17: 654-676.

van Emmerik, I. H., Euwema, M. C., \& Bakker, A. B. 2007. Threats of workplace violence and the buffering effect of social support. Group \& Organization Management, 32: 152-175.

van Harreveld, F., Nohlen, H. U., \& Schneider, I. K. 2015. The ABC of ambivalence: Affective, behavioral and cognitive consequences of attitudinal conflict. In M. P. Zanna \& J. Olson (Eds.), Advances in experimental social psychology, vol. 52: 285-324. New York: Academic Press.

van Knippenberg, B., \& van Knippenberg, D. 2005. Leader self-sacrifice and leadership effectiveness: The moderating role of leader prototypicality. Journal of Applied Psychology, 90: 25-37.

van Vianen, A. E. M., \& De Dreu, C. K. W. 2001. Personality in teams: Its relationship to social cohesion, task cohesion, and team performance. European Journal of Work and Organizational Psychology, 1: 97-120.

Vidyarthi, P. R., Liden, R. C., Anand, S., Erdogan, B., \& Ghosh, S. 2010. Where do I stand? Examining the effects of leader-member exchange social comparison on employee work behaviors. Journal of Applied Psychology, 95: 849-861.

Wang, H., Law, K. S., Hackett, R. D., Wang, D., \& Chen, Z. X. 2005. Leader-member exchange as a mediator of the relationship between transformational leadership and followers' performance and organizational citizenship behavior. Academy of Management Journal, 48: 420-432.

Watson, D., \& Clark, L. A. 1984. Negative affectivity: The disposition to experience aversive emotional states. Psychological Bulletin, 96: 465-490.

Watson, D., Clark, L. A., \& Tellegen, A. 1988. Development and validation of brief measures of positive and negative affect: The PANAS scales. Journal of Personality and Social Psychology, 54: 1063-1070.

Yeow, J., \& Martin, R. 2013. The role of self-regulation in developing leaders: A longitudinal field experiment. The Leadership Quarterly, 24: 625-637.

Zhang, Y., Waldman, D. A., Han, Y. L., \& Li, X. B. 2015. Paradoxical leader behaviors in people management: Antecedents and consequences. Academy of Management Journal, 58: 538-566.

Ziegler, R., Hagen, B., \& Diehl, M. 2012. Relationship between job satisfaction and job performance: Job ambivalence as a moderator. Journal of Applied Social Psychology, 42: 2019-2040.

Zou, X., \& Ingram, P. 2013. The grand duality: Who sees competition within friendship, and how do they perform at work? Academy of Management Proceedings, 2013: 15730. 